Article

\title{
Analysis of Agronomic Drought in a Highly Anthropogenic Context Based on Satellite Monitoring of Vegetation and Soil Moisture
}

\author{
Mehrez Zribi*(D), Simon Nativel and Michel Le Page
}

check for updates

Citation: Zribi, M.; Nativel, S.;

Le Page, M. Analysis of Agronomic

Drought in a Highly Anthropogenic

Context Based on Satellite Monitoring

of Vegetation and Soil Moisture.

Remote Sens. 2021, 13, 2698.

https://doi.org/10.3390/rs13142698

Academic Editor: Yuei-An Liou

Received: 14 June 2021

Accepted: 4 July 2021

Published: 8 July 2021

Publisher's Note: MDPI stays neutral with regard to jurisdictional claims in published maps and institutional affiliations.

Copyright: (c) 2021 by the authors. Licensee MDPI, Basel, Switzerland. This article is an open access article distributed under the terms and conditions of the Creative Commons Attribution (CC BY) license (https:// creativecommons.org/licenses/by/ $4.0 /)$.
CESBIO (CNES/CNRS/INRAE/IRD/UPS), 18 av. Edouard Belin, bpi 2801, CEDEX 09, 31401 Toulouse, France; simon.nativel@univ-tlse3.fr (S.N.); michel.le_page@ird.fr (M.L.P.)

* Correspondence: mehrez.zribi@ird.fr; Tel.: +33-56155-8525

\begin{abstract}
This paper aims to analyze agronomic drought in a highly anthropogenic, semiarid region, the western Mediterranean region. The proposed study is based on Moderate-Resolution Imaging Spectroradiometer (MODIS) and Advanced SCATterometer (ASCAT) satellite data describing the dynamics of vegetation cover and soil water content through the Normalized Difference Vegetation Index (NDVI) and Soil Water Index (SWI). Two drought indices were analyzed: the Vegetation Anomaly Index (VAI) and the Moisture Anomaly Index (MAI). The dynamics of the VAI were analyzed as a function of land cover deduced from the Copernicus land cover map. The effect of land cover and anthropogenic agricultural activities such as irrigation on the estimation of the drought index VAI was analyzed. The VAI dynamics were very similar for the shrub and forest classes. The contribution of vegetation cover (VAI) was combined with the effect of soil water content (MAI) through a new drought index called the global drought index (GDI) to conduct a global analysis of drought conditions. The implementation of this combination on different test areas in the study region is discussed.
\end{abstract}

Keywords: drought index; ASCAT; MODIS; VAI; MAI; GDI

\section{Introduction}

In semiarid areas, drought is a very frequent phenomenon that generates very serious problems, especially for agriculture and food security [1-3]. This scenario often worsens with climate change and an increase in the frequency of extreme events [4-6]. It is essential to properly quantify the intensity and the beginning and end of a drought event to properly assess its effects. In this context, several scientific studies have developed drought indices, mainly based on the detection of climatic anomalies [7-9], mainly related to a deficit in precipitation compared to the average precipitation [10].

Based on meteorological data collected from weather stations, several works have proposed different types of drought indices, such as the Palmer drought severity index (PDSI; [11,12]) or the standardized precipitation index (SPI; [3]). These approaches are often considered operational by meteorological services. However, the information from these approaches, despite their considerable relevance, may be weakened by the low density of rain gauges in some parts of the world. They may also not be fully correlated with the reality of agronomic drought, which directly affects vegetation cover development.

Within this framework, several studies have been developed over the last twenty years based on a time series of remote sensing satellite data [13-15]. In fact, remote sensing has shown high potential to retrieve land surface properties [16-19]. These studies are mainly related to the existence of increasingly longer time series, sometimes more than thirty years that are able to statistically determine climatic anomalies. These data and the products proposed with them mainly describe the dynamics of vegetation cover [20-22], soil water content [23-25], and surface temperature [26]. 
The majority of these studies use data from optical sensors, such as Advanced Very High Resolution Radiometer (AVHRR), SPOT-Vegetation, Moderate-Resolution Imaging Spectroradiometer (MODIS), and Land Satellite (LANDSAT), to identify anomalies in the growth of vegetation cover. They mainly use the Normalized Difference Vegetation Index (NDVI) [27], which shows a strong correlation with the photosynthetic activity of plant cover. This index is expressed by NDVI = (RNIR - RRED $) /($ RNIR + RRED) where RNIR is the near-infrared (NIR) reflectance and RRED is the red reflectance. The vegetation condition index (VCI), which normalizes NDVI between the minimum and maximum at a site, is one of the most widely used indices for monitoring drought [20]. It has been tested in different regions of the world, showing a strong ability to characterize droughts [28-30]. Other types of indices, such as the Vegetation Anomaly Index (VAI), based on NDVI have also shown an ability to detect vegetation cover anomalies [31,32]. They have also been linked to agricultural production and different climatic phenomena, such as El Niño [33]. Crop temperature is also a good indicator of vegetation health [13]. Healthy vegetation evapotranspiration at its maximum rate reduces the surface temperature, while waterstressed vegetation reduces its activity, thus reducing evapotranspiration and increasing the surface temperature. Several approaches also have profited from the brightness temperature from satellites or its derived land surface temperature to calculate temperature anomalies. Kogan et al. [13] proposed calculating the VHI (vegetation health index), which takes into account the anomalies of vegetation vigor and an eventual anomaly due to vegetation stress.

On the other hand, other indices have used satellite measurements, particularly with microwave sensors such as ASCAT/METOP, SMOS, and SMAP, to analyze anomalies in soil moisture profiles [23-25].

Composite indices using satellite observations were proposed taking into account combined observations [26,34-38]. Mu et al. [26] proposed the drought severity index (DSI), combining the vegetation anomaly index and an evapotranspiration anomaly index, which has shown considerable potential for the quantification of drought in different climatic regions. Despite the strong contribution of these indices, they do not generally consider two essential aspects of the functioning of land surface states: the first aspect is the difference in the dynamics between the agricultural and natural contexts, and the second aspect is related to the weight of an index in relation to the seasonal climatic context, especially in arid or semiarid climates with the seasonality of precipitation and vegetation cover development. The share of contribution of the components is generally considered unknown, so that it is commonly considered equal [26].

In terms of the Mediterranean climate, characterized by frequent droughts, northwest Africa and southern Spain are particularly affected by droughts. In fact, in addition to this climatic aspect, it is one of the areas most affected by water scarcity in the world [8]. Thus, understanding and describing agronomic drought are essential. The objective of this paper is to understand the potential of remote sensing data to monitor vegetation cover and soil water content, especially in a highly anthropogenic context that requires vigilance to distinguish climatic effects from other effects that are more related to human activity, especially in agricultural areas. This analysis was enhanced by the development of a new index combining the VAI and Moisture Anomaly Index (MAI) indices, where the share of the two components takes into account seasonal specificities of vegetation development and water content in the soil.

The proposed study is mainly based on TERRA-MODIS and ASCAT/METOP satellite data. Section 2 presents the study site, the database and the methods considered in this study. Section 3 illustrates the results and discussions. Our conclusions are presented in Section 4. 


\section{Materials and Methods}

\subsection{Database}

\subsubsection{TERRA-MODIS Data}

In this study, we used 250-m spatial resolution, 16-day composites of MODIS NDVI data (MOD13Q1, collection 5). This product was retrieved from atmosphere-corrected [39], daily, bidirectional surface reflectance observations using a compositing technique based on product quality assurance metrics to remove low-quality pixels. The $250-\mathrm{m}$ spatial resolution is the finest available from the MODIS NDVI dataset, and the 16-day composite was selected to ensure a high probability of having the best quality pixel representing the NDVI within each 16-day period and without the effect of clouds [40]. Here, we used this product to analyze the influence of drought between September 2000 and the end of 2020.

\subsubsection{ASCAT Data}

The ASCAT scatterometer radar is one of the 12 instruments carried by the ESA's METOP-A, METOP-B, and METOP-C satellites and operates in the C-band (5.3 GHz), in the vertical polarization. Over land, the measured radar backscattering coefficient depends on the soil moisture, surface roughness, vegetation characteristics, and incidence angle of the transmitted radar beam. The soil moisture data are retrieved from the backscattering coefficient using a change detection method developed at the Institute of Photogrammetry and Remote Sensing (IPF), Vienna University of Technology (TU-Wien) [41,42]. The derived soil moisture product, expressed in relative units and referred to as 'surface soil moisture' (ms), represents the water content in the first $5 \mathrm{~cm}$ of the soil and ranges between the extremes corresponding to totally dry conditions and a saturated water capacity. The spatial resolution is defined by cells of approximately $50 \mathrm{~km}$, with a grid spacing of $12.5 \mathrm{~km}$, and the temporal resolution of the data varies between approximately two and three measurements per week.

The Soil Water Index data (SWI) was derived from m using, Equation (1), and represents the root-zone soil moisture content in the first meter of the soil in relative units ranging between wilting point and field capacity [43].

$$
\operatorname{SWI}(\mathrm{t})=\frac{\sum_{\mathrm{i}} \mathrm{ms}(\mathrm{ti}) \mathrm{e}^{-(\mathrm{t}-\mathrm{ti}) / \mathrm{T}}}{\sum_{\mathrm{i}} \mathrm{e}^{-(\mathrm{t}-\mathrm{ti}) / \mathrm{T}}} \text { for } \mathrm{ti} \leq \mathrm{t}
$$

where $\mathrm{ms}$ is the surface soil moisture estimate from the ASCAT scatterometer at time $t_{i}$. The parameter T, called the characteristic time length, represents the time scale of soil moisture variations in units of time. T equal to 20 days has shown the best fit to ground measurements. These products have already been used and validated in the studied site [43].

\subsubsection{Copernicus Land Cover Map}

The land use map proposed by the Copernicus program [44] provides spatial information for different land cover classes or natural cover of land surfaces, such as forests, agricultural areas, wetlands, and urban areas. To simplify our study, we considered only the land cover map proposed in 2020, assuming little change in land cover at the western Mediterranean scale. Figure 1 illustrates the land cover map for our study site, with four main land cover types: bare soil often related to desert areas, crop agricultural areas, shrub and herbaceous vegetation, and forests. 


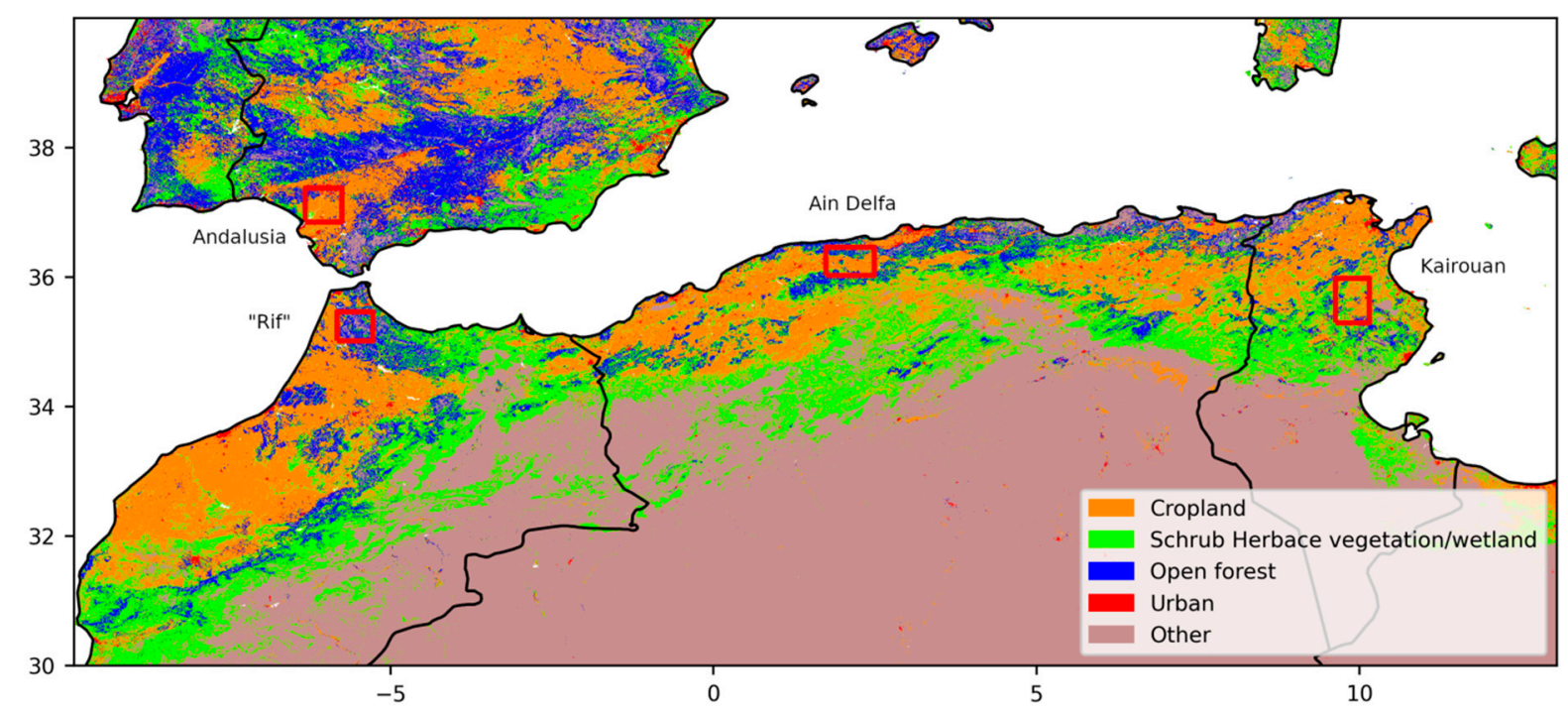

Figure 1. Simplified land cover map based on the Copernicus land cover map. The red boxes indicate the four test areas of Andalusia, Spain; Rif, Morocco; Ain Defla, Algeria; Kairouan, Tunisia.

Three types of land use were identified for the analysis of drought proposed in this study: agricultural areas, shrub and herbaceous vegetation areas, and open forest areas. A part of this analysis was based on an evaluation of the effects of land use at four sites with different characteristics in terms of land use, climatology, and type of agriculture. The four sites were the region of Kairouan in Tunisia, characterized by rainfed agriculture, a low rainfall amount (300 mm per year); the region of Ain Defla in Algeria (640 mm per year); the Rif, a mountainous region of northern Morocco, with a high precipitation amount ( $800 \mathrm{~mm}$ per year); and Andalusia in southern Spain (480 $\mathrm{mm}$ per year) with intensively irrigated agriculture. The climate of Kairouan is semiarid (BSh on the KöppenGeiger classification), while the three other areas have a Mediterranean climate (CSa). Table 1 illustrates the percentages of crops, shrubs, herbaceous vegetation and open forests, and also the average altitude for each site.

Table 1. Percentages of crops, shrubs, herbaceous vegetation, and open forests and average altitude at the four studied sites.

\begin{tabular}{ccccc}
\hline Site & Crops & Shrub and Herbaceous Vegetation & Open Forest & Average Altitude (m) \\
\hline Kairouan & $48 \%$ & $35 \%$ & $12 \%$ & 196 \\
Ain Defla & $48 \%$ & $24.5 \%$ & $24.5 \%$ & 508 \\
Rif & $11 \%$ & $17 \%$ & $49 \%$ & 470 \\
Andalusia & $69 \%$ & $8 \%$ & $14 \%$ & 29 \\
\hline
\end{tabular}

These sites were approximately $50 \times 50 \mathrm{~km}$ with the different land uses (crops, shrub/herbaceous vegetation, and open forests), and the drought index VAI was calculated for the different land uses at a monthly scale. We assumed that the climate context was the same among the three land covers since the regions are limited in size.

\subsubsection{Irrigation Map}

Figure 2 illustrates the Global Map of Irrigated Area (GMIA) version 5 for the study area [45]. This product was initially developed by Döll and Siebert [46] and then enhanced to obtain 5 arc minutes resolution maps [47]. The reference years for the statistics used to establish the map differ between countries but in most cases, the data refer to the period 2000-2008. Despite several shortcomings detailed by the authors, this map remains the FAO reference today. Figure 2 represents the percentage of area equipped with irrigation from 0 to $100 \%$. The $0 \%$ corresponds to rainfed areas. The $100 \%$ corresponds to areas fully irrigated. 


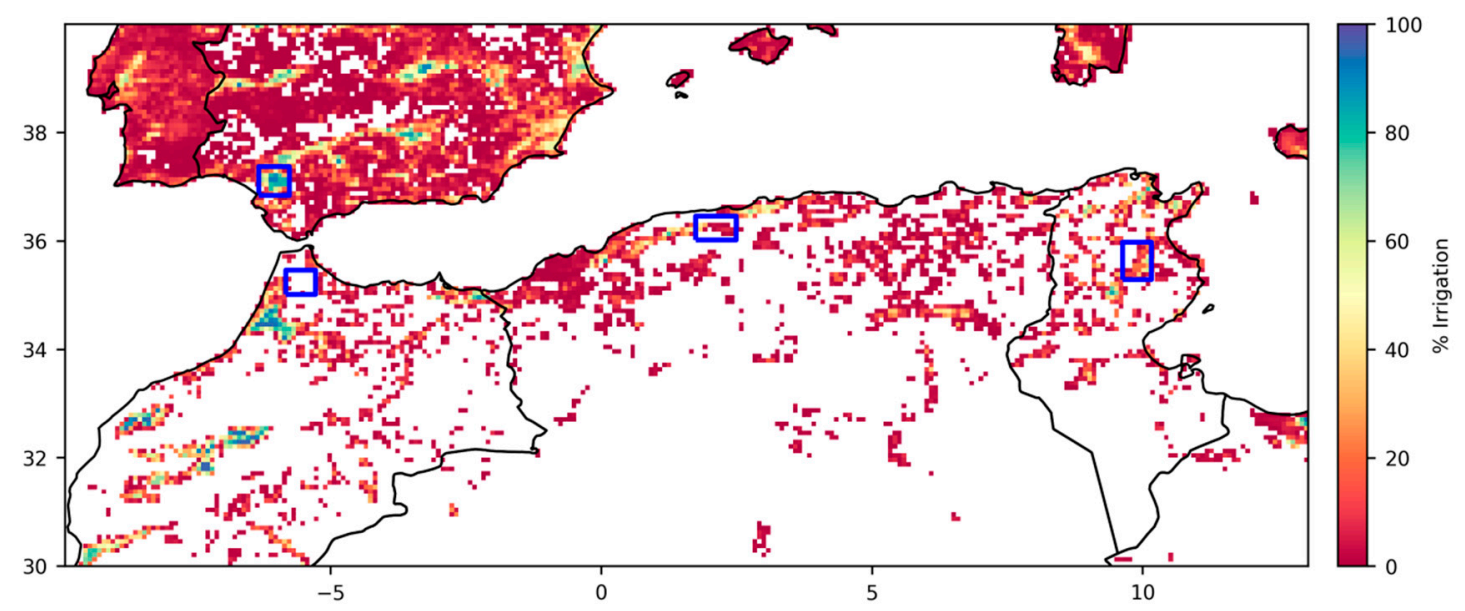

Figure 2. The percentage of irrigated area according to Siebert et al. [47].

\subsection{Methodology}

Three drought indices were used in this study to understand the drought phenomena, and the two VAI and MAI indices had already been tested in the study region [37]. The global drought index (GDI) was proposed in this study.

\subsubsection{Vegetation Anomaly Index (VAI)}

This index is based on statistics derived from the NDVI MODIS time series and is referred to as the 'vegetation anomaly index' (VAI) [31], written as:

$$
\mathrm{VAI}_{\mathrm{i}}=\frac{\mathrm{NDVI}_{\mathrm{i}}-\left(\mathrm{NDVI}_{\mathrm{i}}\right)_{\text {mean }}}{\sigma_{\mathrm{i}}}
$$

where $\mathrm{NDVI}_{\mathrm{i}}$ is the NDVI estimate for a given month $\mathrm{i}$, $\left(\mathrm{NDVI}_{\mathrm{i}}\right)_{\text {mean }}$ is the mean value of the NDVI during month $i$, derived from the previously described 20 years of NDVI time series, and $\sigma_{i}$ corresponds to the standard deviation of the NDVI values estimated for month i over the same 20-year period.

When the VAI is greater than zero, it means that NDVI is higher than normal, corresponding to a bountiful season. When the VAI is negative, NDVI is lower than normal, which in many cases may be attributed to a drought or a period with a lack of precipitation. We have computed this index for each processed pixel.

\subsubsection{Moisture Anomaly Index (MAI)}

With vegetation development anomalies in the context of drought conditions, the soil moisture content is complementary information essential for detecting agronomic drought.

For soil water content, we propose the use of ASCAT SWI products. With a $12.5 \mathrm{~km}$ spatial resolution, this product remains highly adapted to the monitoring of climatic effects related to precipitation. The MAI drought index [23] is based on statistics derived from the SWI time series and is referred to as the 'Moisture Anomaly Index' (MAI), written as:

$$
\mathrm{MAI}_{\mathrm{i}}=\frac{\mathrm{SWI}_{\mathrm{i}}-\left(\mathrm{SWI}_{\mathrm{i}}\right)_{\text {mean }}}{\sigma_{\mathrm{i}}}
$$

where $\mathrm{SWI}_{\mathrm{i}}$ is the SWI estimate for a given month $\mathrm{i},\left(\mathrm{SWI}_{\mathrm{i}}\right)_{\text {mean }}$ is the mean value of the SWI during month $\mathrm{i}$, derived from the previously described 13 years of SWI time series, and $\sigma_{i}$ corresponds to the standard deviation of the SWI values estimated for month i over the same 13-year period.

When the MAI is greater than zero, a higher than normal SWI value is indicated, corresponding to a wet profile and the absence of drought. When the MAI is negative, 
a lower than normal SWI value, which is probably the result of drought or a period with a lack of precipitation, is indicated.

\subsubsection{Global Drought Index (GDI)}

To consolidate drought detection, we proposed a mixed index based on the two indices VAI and MAI [48]. This type of combination has been proposed by different studies [26,34]. However, as stated in the introduction, the weightings of the two indices are generally based on simple addition without discussing different weights.

The index is written as:

$$
\begin{aligned}
& \operatorname{Ind}_{\mathrm{i}}=\alpha_{\mathrm{i}} \mathrm{VAI}_{\mathrm{i}}+\beta_{\mathrm{i}} \mathrm{MAI}_{\mathrm{i}} \\
& \mathrm{GDI}_{\mathrm{i}}=\frac{\operatorname{Ind}_{\mathrm{i}}-\left(\mathrm{Ind}_{\mathrm{i}}\right)_{\text {mean }}}{\sigma_{\text {Ind, } \mathrm{i}}}
\end{aligned}
$$

where $\alpha i$ and $\beta i$ are the weights given to the two drought indices during month $i . \operatorname{Ind}_{i}$ is the Ind estimate for a given month i $\sigma_{\text {Ind,i }}$ corresponds to the standard deviation of the Ind values estimated for month i over the same 13-year period. The $\mathrm{GDI}_{\mathrm{i}}$ is a dimensionless index ranging theoretically from negative values (drier than normal) to unlimited positive values (wetter than normal).

For the three drought indices, MAI, VAI, and GDI, we could consider a context of severe drought if the index was less than -1 , a context close to normal for indices between -1 and 1 , and finally in a wet situation for an index superior to 1 .

Droughts are generally marked by a decrease in NDVI and SWI products. In a semiarid climate, we observe periods of the year where very low NDVI or SWI are present independently of drought. This is typical of the summer season. However, in the autumn and spring seasons, the averages of one of the two parameters are also equally low. In this context, weights $\alpha \mathrm{i}$ and $\beta \mathrm{i}$ could be calculated according to the mean level of vegetation or moisture in month $i$. This means that a higher weight should be given to the vegetation anomaly when the vegetation is well developed. This is expressed by Equation (5), where $i$, min and max of NDVI correspond to the 12 months of the year. Thus, a low $\alpha \mathrm{i}$ is given to poorly vegetated months; one weighs the VAI more than the MAI in the calculation of the global drought index. This could be introduced in the weights proposed for the two indices MAI and VAI in the calculation of GDI.

$$
\alpha_{\mathrm{i}}=\alpha_{0}+\left(1-\alpha_{0}\right) \frac{\mathrm{NDVI}_{\mathrm{i}}-\mathrm{NDVI}_{\min }}{\mathrm{NDVI}_{\max }-\mathrm{NDVI}_{\text {min }}}
$$

where $\mathrm{NDVI}_{\mathrm{i}}$ is the NDVI estimate for a given month $\mathrm{i}, \mathrm{NDVI}_{\min }$ is the minimum value of the NDVI for the 12 months, derived from the previously described 20 years of NDVI time series, and $\mathrm{NDVI}_{\max }$ is the maximum value of the NDVI for the 12 months, derived from the previously described 20 years of the NDVI time series.

$$
\beta_{\mathrm{i}}=\beta_{0}+\left(1-\beta_{0}\right) \frac{\mathrm{SWI}_{\mathrm{i}}-\mathrm{SWI}_{\min }}{\mathrm{SWI}_{\max }-\mathrm{SWI}_{\min }}
$$

where $\mathrm{SWI}_{\mathrm{i}}$ is the $\mathrm{SWI}$ estimate for a given month $\mathrm{i}, \mathrm{SWI}_{\min }$ is the minimum value of the SWI for the 12 months, derived from the previously described 13 years of SWI time series, and $\mathrm{SWI}_{\max }$ is the maximum value of the SWI for the 12 months, derived from the previously described 13 years of SWI time series.

Interestingly, as these values are calculated independently, adding $\alpha \mathrm{i}$ and $\beta \mathrm{i}$ is not equal to 1, so the normalization of Equation (4) is necessary to obtain the final GDI.

\subsubsection{Statistical Parameters}

In the present study, the comparison between indices is evaluated with the Pearson's correlation, and the RMSE (Root Mean Square Error). 
Pearson's correlation

$$
R=\frac{\sum_{i=1}^{N}\left(x_{i}-\bar{x}\right)\left(y_{i}-\bar{y}\right)}{\sqrt{\sum_{i=1}^{N}\left(x_{i}-\bar{x}\right)^{2}} \sqrt{\sum_{i=1}^{N}\left(y_{i}-\bar{y}\right)^{2}}}
$$

where $x_{i}$ and $y_{i}$ are individual samples taken at points indexed with the variable $i, N$ is the number of samples, $\bar{x}$ is the mean of the samples $x_{i}$, and $\bar{y}$ is the mean of the samples $y_{i}$.

RMSE (Root Mean Square Error)

$$
R M S E=\sqrt{\frac{1}{N} \sum_{i=1}^{N}\left(P_{i}-O_{i}\right)^{2}}
$$

where $\mathrm{N}$ is the number of data samples, $\mathrm{P}_{\mathrm{i}}$ is the first index value of sample $\mathrm{i}$, and $\mathrm{O}_{\mathrm{i}}$ is the second index value of sample i.

The data are checked to ensure they follow a normal distribution, and for their significance, prior to all analyses. The intercomparison between indices was assessed using the RMSE error.

\section{Results and Discussions}

\subsection{Analysis of VAI Variation Function of Land Use}

Drought indices using NDVI satellite time series are generally calculated in study areas or pixels, taking into account only the NDVI level. However, the temporal variations in the NDVI are strongly related to the type of land use. Thus, it is legitimate to ask what the effect of these land-use types is on the level of the drought index. This is particularly the case in agricultural areas, which can be affected by additional factors to climatic conditions, such as human activity, presence or absence of irrigation, and decisions made by farmers in the context of extreme conditions. These anthropogenic factors could affect the identified anomalies. Thus, the objective of this section is to evaluate the VAI index for the different types of land use and to assess the behaviors of each.

Figure 3 shows a cross-comparison of the VAI between the different land uses at the four test sites identified in Section 2.1. All monthly VAI estimates are displayed, each point corresponds to the VAI calculated for a given month. In each figure, the statistical parameters $\mathrm{R}^{2}$, RMSE, and the linear relation between the VAI of the two considered land uses ( $\mathrm{Y}=\mathrm{a} . \mathrm{X}, \mathrm{a}$ is the slope) are illustrated. For the case of two land uses with very close VAI indices, we should find an RMSE close to zero, an $\mathrm{R}^{2}$ close to 1 , and a slope close to 1.

Apart from Kairouan, the slope between the cropland class and the two other crop classes was lower than 0.9 . The slope was steeper for forests. The observed behaviors could be explained by a maximum anthropogenic effect in agricultural zones, which probably strengthens the extremes. In fact, in the event of drought, in several regions, including irrigated areas, farmers do not sow if the first rainfall is absent and may even abandon the fields to animals during a very dry season. This human action accentuates the decline in NDVI and thus the effects of drought. Human influence is obviously less important in natural areas.

On the other hand, the correlation when comparing the VAI values of crop zones with other cover types showed very distinctive patterns. The semiarid area with limited irrigation in Kairouan showed high correlations $\mathrm{R}^{2}$ of 0.91 and 0.88 between crops and shrub/herbaceous vegetation and crops and forests, respectively, and little dispersion (RMSE of 0.2 and 0.23 , respectively). In contrast, Andalusia had low correlations and high dispersion. The Moroccan and Algerian sites had moderate correlations. These correlations were weakened by anthropogenic effects, particularly due to irrigation, which could be important in some areas. 

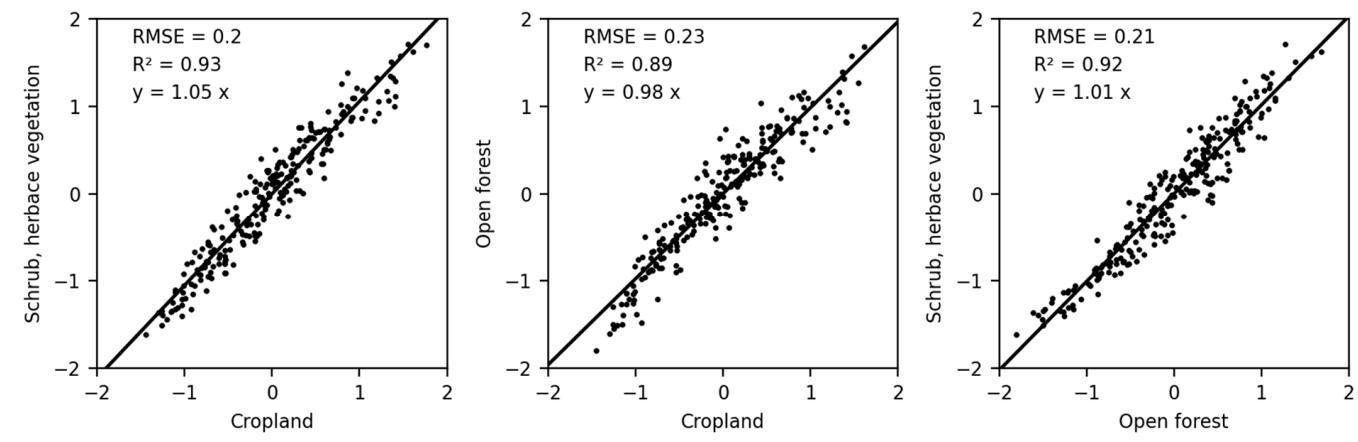

(a)
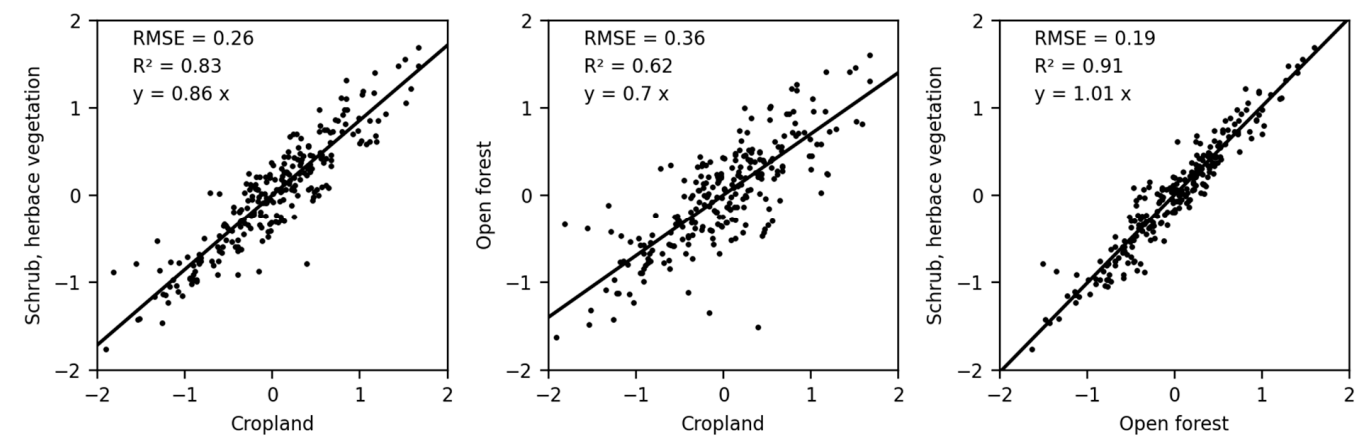

(b)
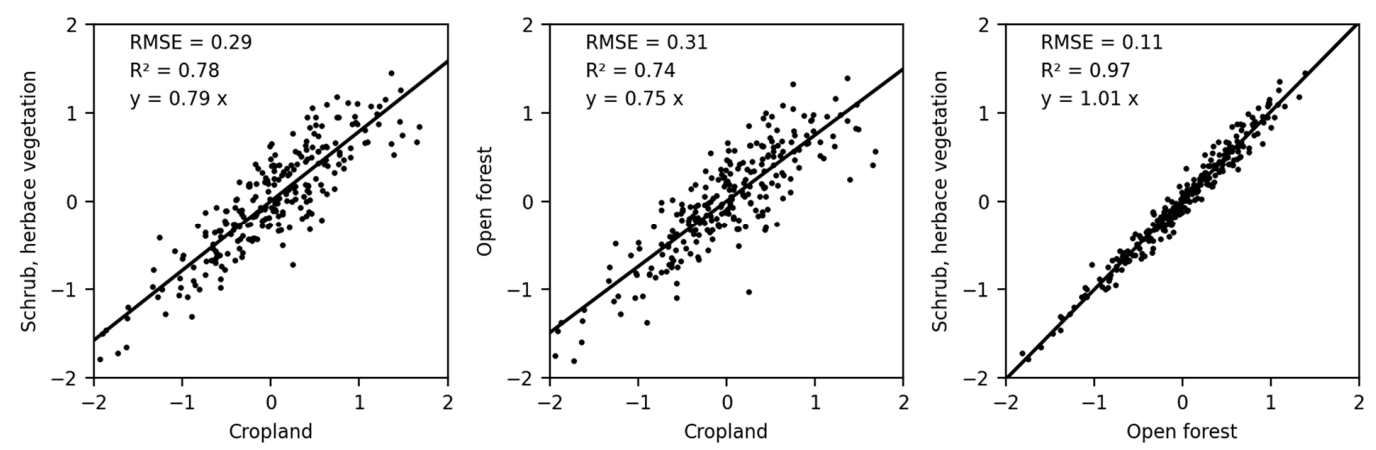

(c)
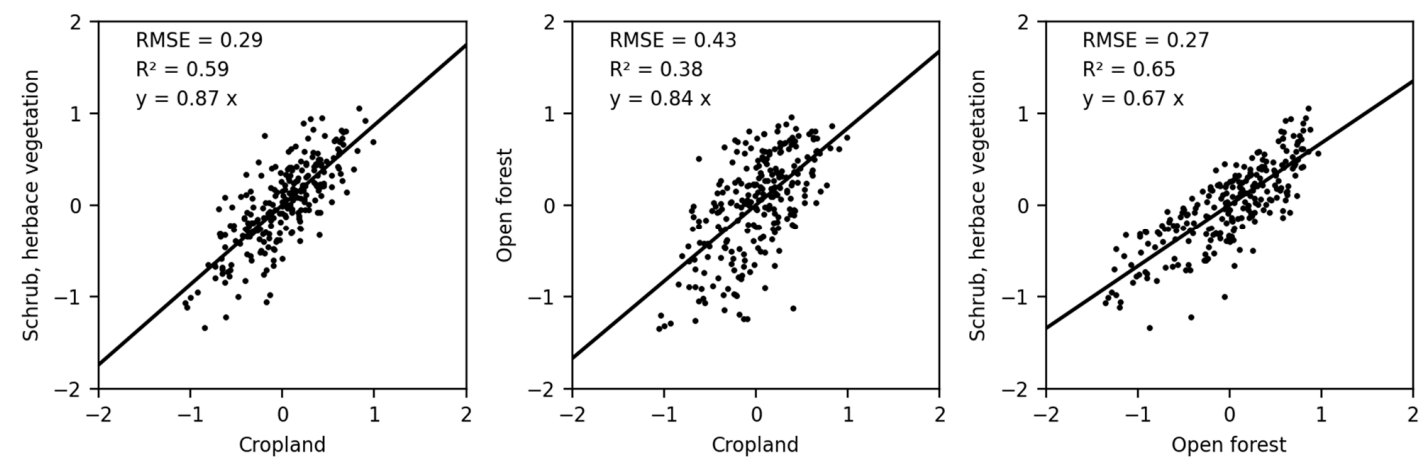

(d)

Figure 3. Intercomparison between the VAI values for the different land uses (crop, shrub, and open forests), (a) Kairouan, Tunisia; (b) Ain Defla, Algeria; (c) Rif, Morocco; (d) Andalusia, Spain. 
For studied sites, we observed a slope generally close to 1 between the VAI estimated for shrub/herbaceous vegetation and that estimated for forests. In Andalusia, this slope was weaker. The limited \% of these land uses could explain this result; however, it could also have occurred based on the dominance of olive groves in this area. A strong correlation was also observed between shrubs and forests for the first three sites, Kairouan, Ain Dafla, and Rif. This correlation $\mathrm{R}^{2}$ ranged between 0.9 and 0.97 for the three test sites.

Distributions of the VAI for the three types of land use at the four sites (Figure 4) confirmed the first results of the comparisons, with generally similar behavior for shrubs, herbaceous vegetation, and forests. This figure also shows a large contrast between the different regions. In particular, the Andalusia distribution was concentrated around an average situation, while the flattened Kairouan's distribution shows the frequent recurrence of extreme events.

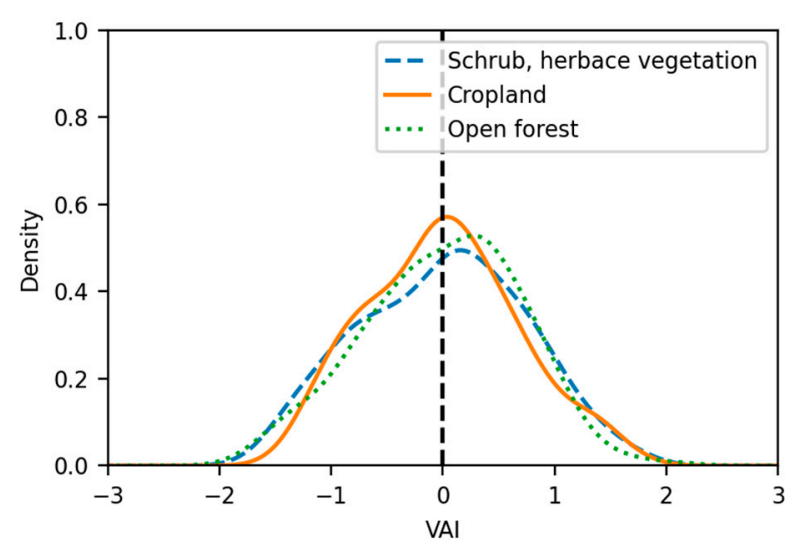

(a)

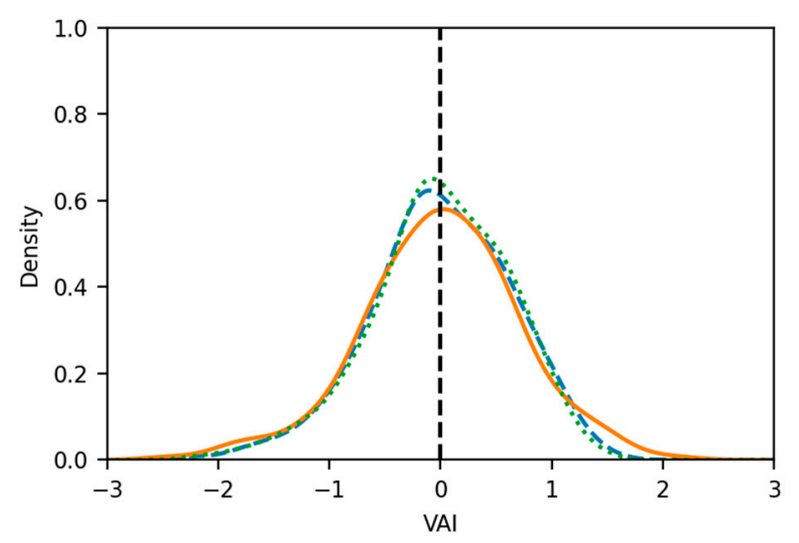

(c)

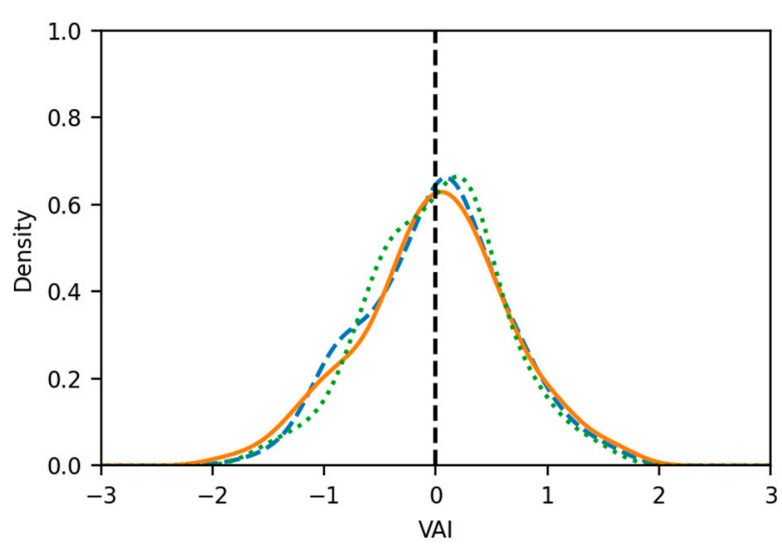

(b)

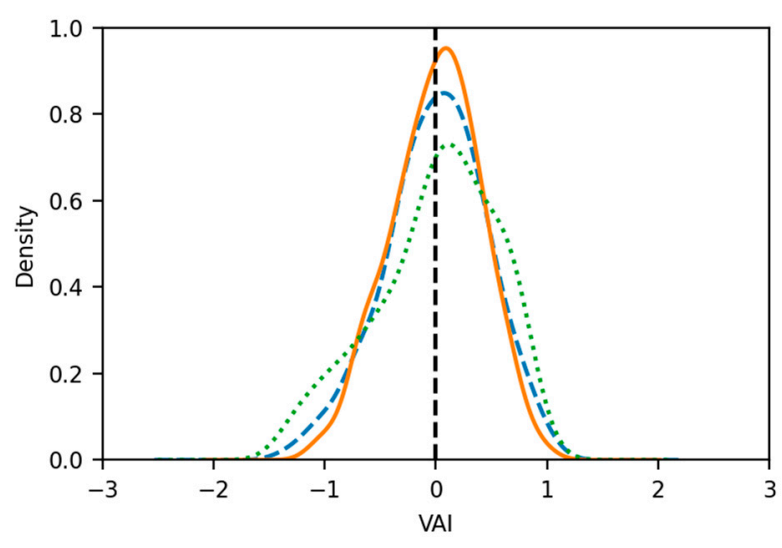

(d)

Figure 4. Distributions of the VAI values for the three land uses (crops, shrub and herbaceous vegetation, and open forest), (a) Kairouan; (b) Ain Dafla; (c) Rif; (d) Andalusia.

In conclusion, we observe a strong resemblance between the two classes shrub, herbaceous vegetation and openforest, compared to cropland with rather different behaviors. So, two global classes were used to illustrate the VAI, one class of agricultural areas and a second class, natural vegetation merging the two classes of natural areas (shrub, herbaceous vegetation and forest). Figure 5 illustrates the two proposed classes, cropland and natural vegetation over the studied region. The effect of topography was not analyzed in this study. However, it could have an effect on drought-related behaviors. In fact, natural areas are more present in areas with high altitudes than in valleys. These areas also generally have lower temperatures, which could allow for better resistance to drought. 


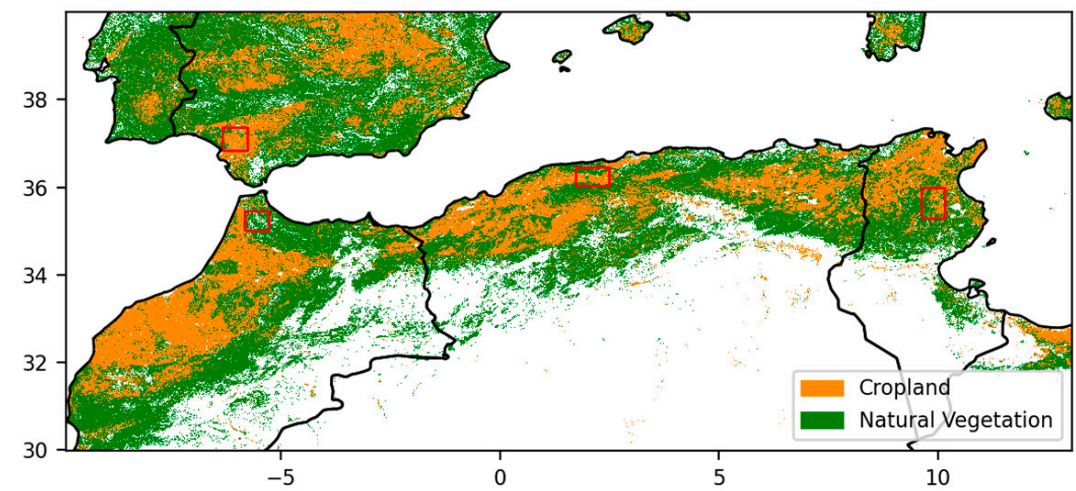

Figure 5. Simplified land use map with two classes: cropland and natural vegetation.

Figure 6 illustrates the VAI maps calculated based on these two land-use classes in March for four specific years, two dry years (2001 and 2016) and two wet years (2006 and 2018). The drought index calculated in the natural zones was a priori without anthropogenic effects and was thus the most correlated to the climatic effects of drought.

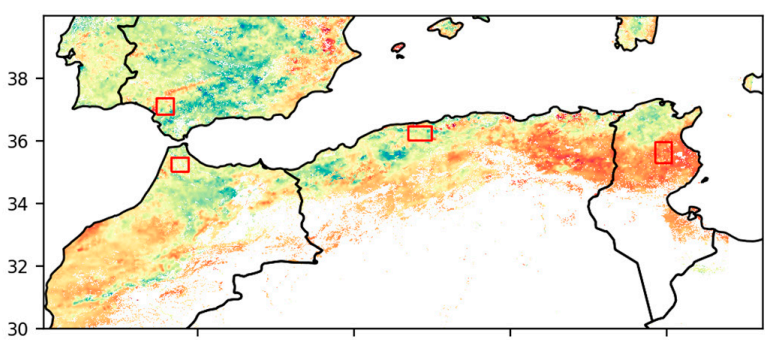

2001
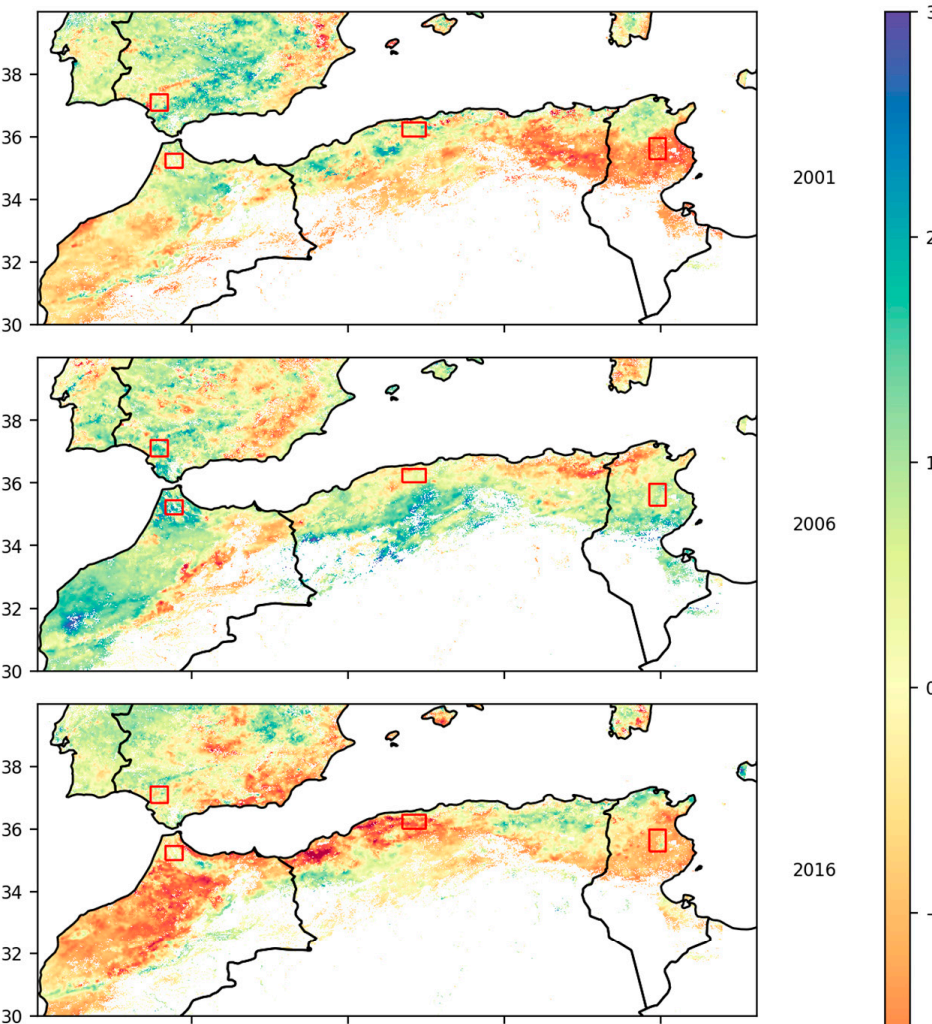

2016

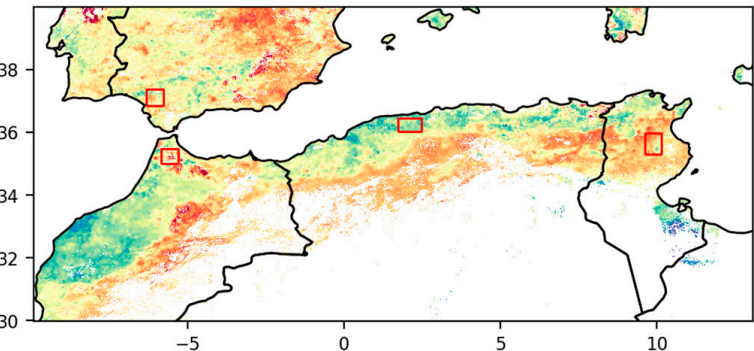

2018

Figure 6. Maps of the VAI combining calculations for crops and natural areas over the studied region, in March 2001, March 2006, March 2016, and March 2018. 
The VAI and irrigation mapping are magnified for two sites, Kairouan (Figure 7) and Andalusia (Figure 8). The first site (Kairouan) had limited irrigated agriculture. The second site (Andalusia) was characterized by intense irrigation. Our objective was to observe the differences between VAI indices in the context of combined effects related to land use (crop or natural vegetation) and then the presence or not of irrigation in the crop context.
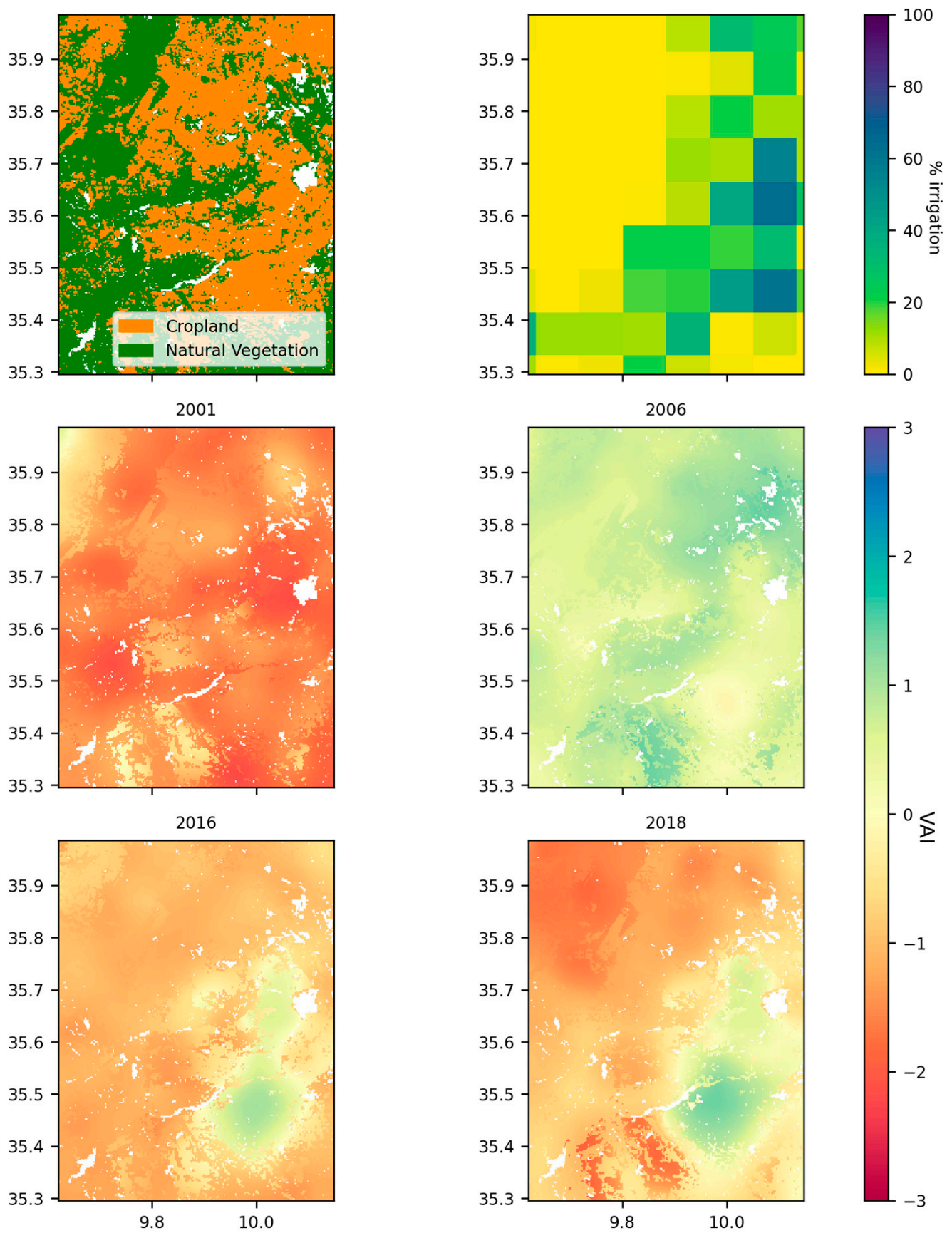

Figure 7. Maps of land use, irrigation, and VAI maps for March 2001, March 2006, March 2016, and March 2018, over the Kairouan site. 

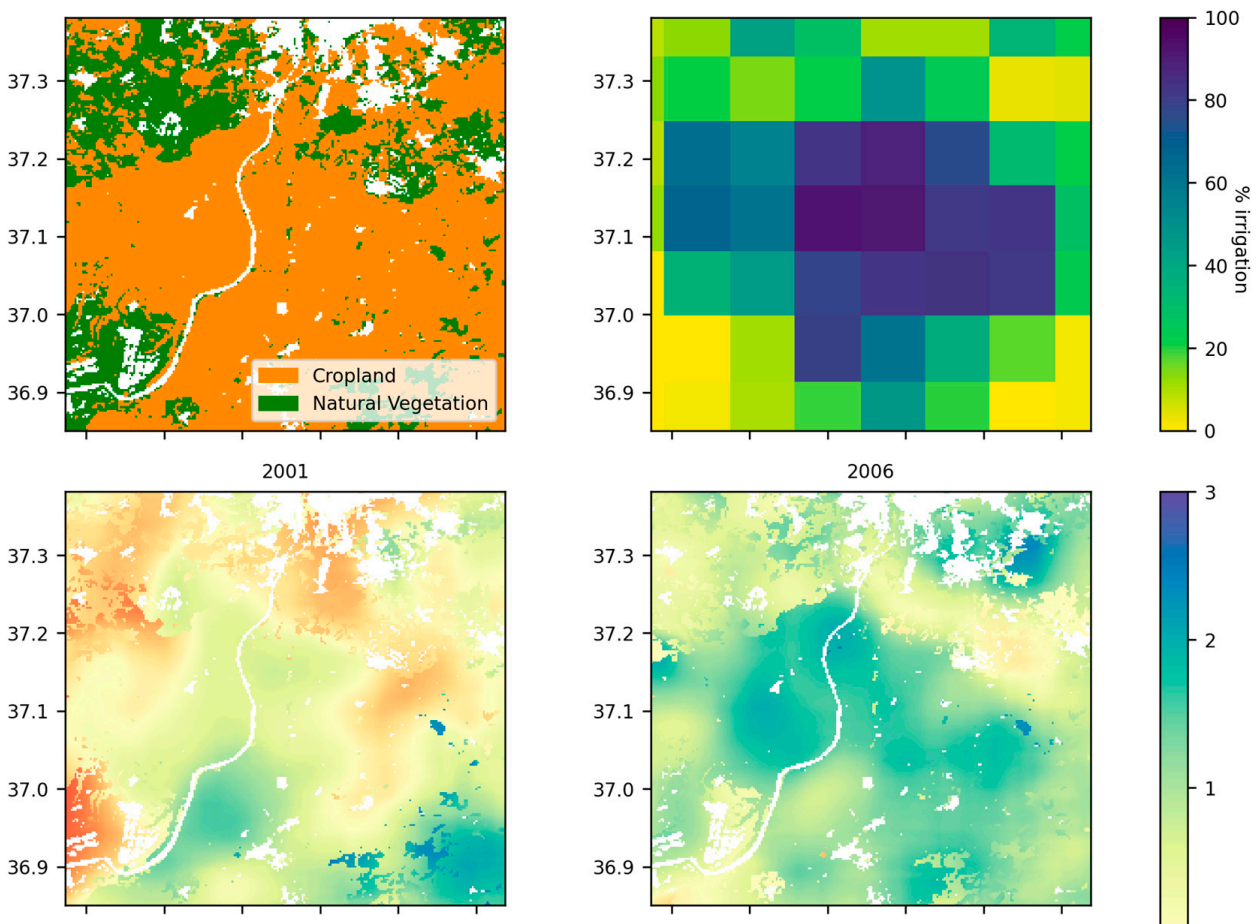

2016

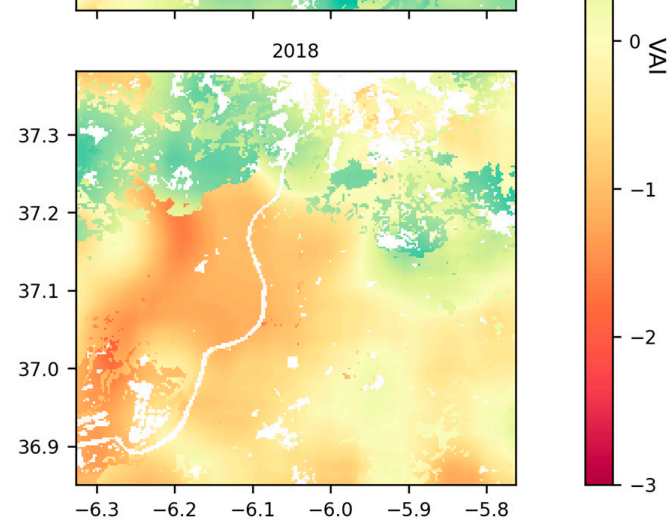

Figure 8. Maps of land use, irrigation, and VAI for March 2001, March 2006, March 2016, and March 2018 over the Andalusia site.

At the first site, for the considered dates, we observed small differences between the estimated VAI for cropland and natural surfaces for some dates. In the context of the two extremes, in 2001 with an exceptional drought and in 2018 with wet conditions, the two types of land uses showed approximately the same behavior.

At the second site, there was clearly a strong difference between the drought indices found in the natural and cropland areas. There were even reversed trends for some dates, such as 2016. This effect was particularly accentuated due to the highly irrigated context. The irrigation map over the study area confirmed this accentuated effect on the regions marked by the highest rate of irrigation.

In the context of this study, the considered irrigation map is the FAO reference map. However, it is based on data collected more than fifteen years ago. This could have some lags compared to the current context, generally marked by an intensification of irrigation, especially in North Africa. This could generate some errors in the interpretation of the behavior results of irrigated and non-irrigated areas.

Over the Andalusia site, Figure 9 illustrates the intercomparison between the estimated VAI in areas irrigated at $+20 \%$ and other rainfed agricultural areas or areas with irrigation levels below $20 \%$. Higher extremes were generally observed for areas with no or low irrigation levels. This result could be explained by a climate with more extreme 
conditions related to drought or heavy rainfall. The irrigated context was less variable (amplitude of 1.88 versus 2.65) because of the organized irrigation management. Both curves had a negative trend, which was much higher for non-irrigated areas $(-0.0006$ per month) than for irrigated areas $(-0.0013)$. This result could be explained by the strong conversion of seasonal crops to olive groves in Andalusia. According to agricultural statistics, the share of olive groves increased by 30\% from 1993 to 2018, while the share of seasonal crops decreased by $43 \%$ during the same period [49]. Marked differences between the two curves were observed, especially in the summer months. In 2005 and 2012, the VAI of the irrigated area was significantly higher (>0.5) than that of the non-irrigated area. In 2005, less rain occurred than had previously in the past 20 years, and according to agricultural statistics, the sunflower, a typical summer crop that represents an average of $14 \%$ of the total cropped area of Andalusia, experienced a severe drop in the cropped area in those two years. Jimenez et al. [34] also recorded a high percentage of crop damage during those years. In the summer months of 2007, 2008, 2013, and 2018, the situation was the opposite. The VAI of the irrigated area was significantly inferior $(<-0.5)$ to that of the non-irrigated area. Yearly agricultural statistics do not provide a satisfactory explanation of this scenario. Jimenez et al. [34] did not report crop damage, and there was no high level of distress in terms of reservoir storage. However, the yearly rain records of 2013 and 2018 were substantially above the mean, which could explain the survival of vegetation in the summer and probably the early harvest of winter crops.

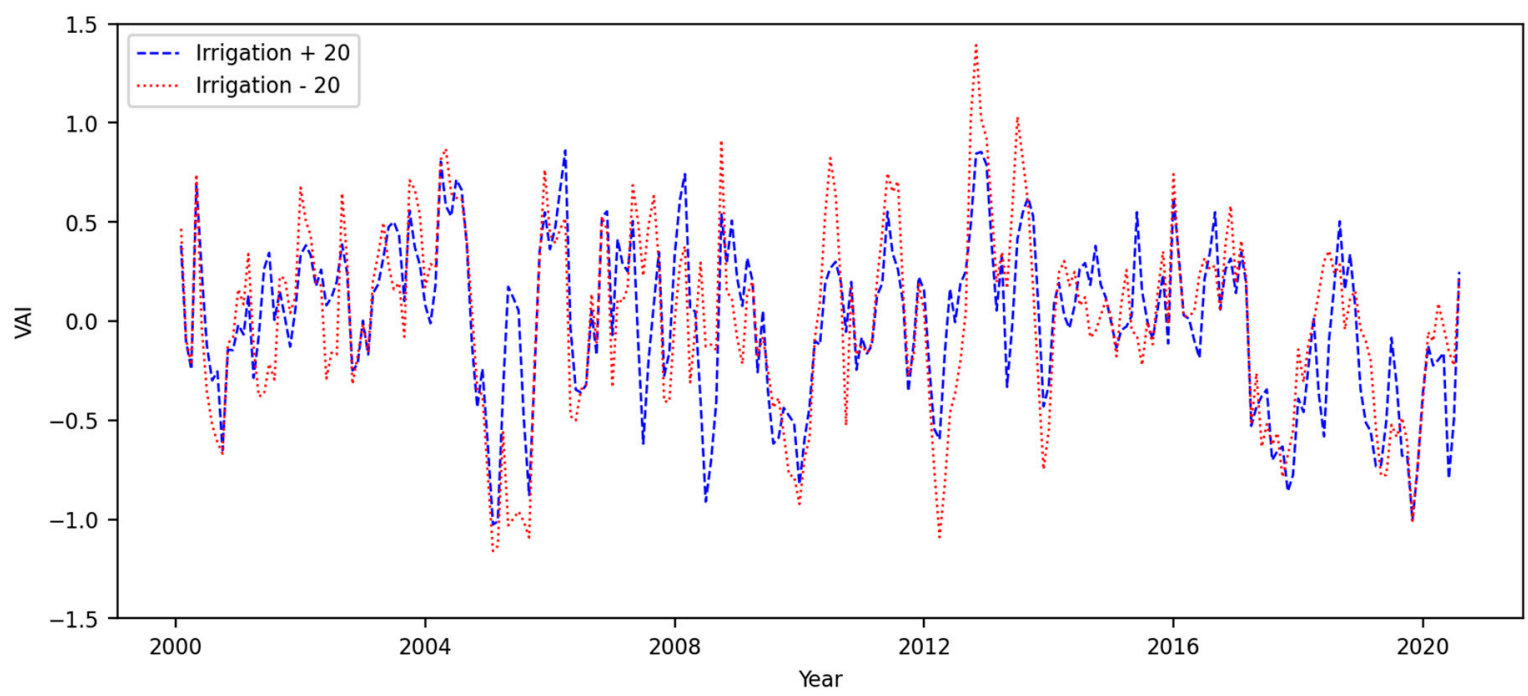

Figure 9. VAI time series at the Andalusia site in pixels with more than $20 \%$ of irrigated area and in pixels mainly rainfed or less than $20 \%$ of irrigated area.

\subsection{Application of GDI Index}

Figure 10 illustrates the NDVI, SWI, VAI, and MAI estimated at two test sites, Kairouan and Andalusia. It is important to note that with a resolution of $12.5 \mathrm{~km}$, the SWI cannot be identified in a completely separate way between the two types of land use. This scenario explains the strong similarities in the time series for the two types of land cover in fragmented landscapes, while there was a higher contrast in adjacent landscapes. 

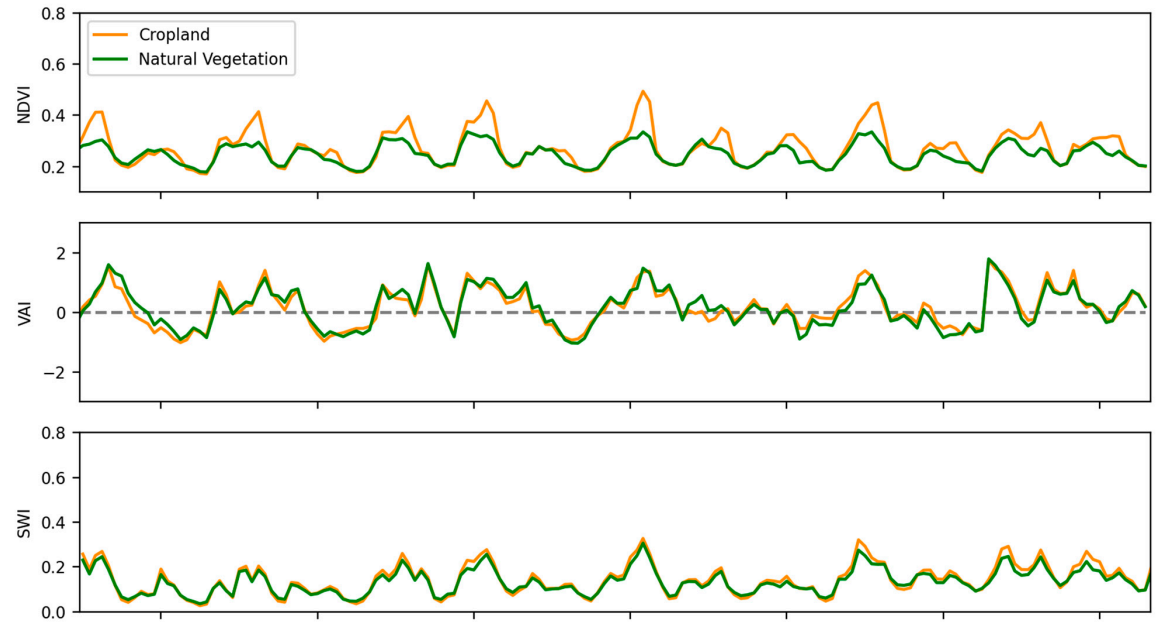

:

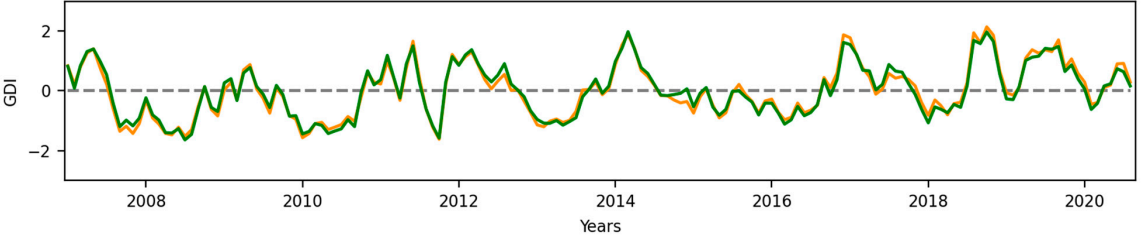

(a)
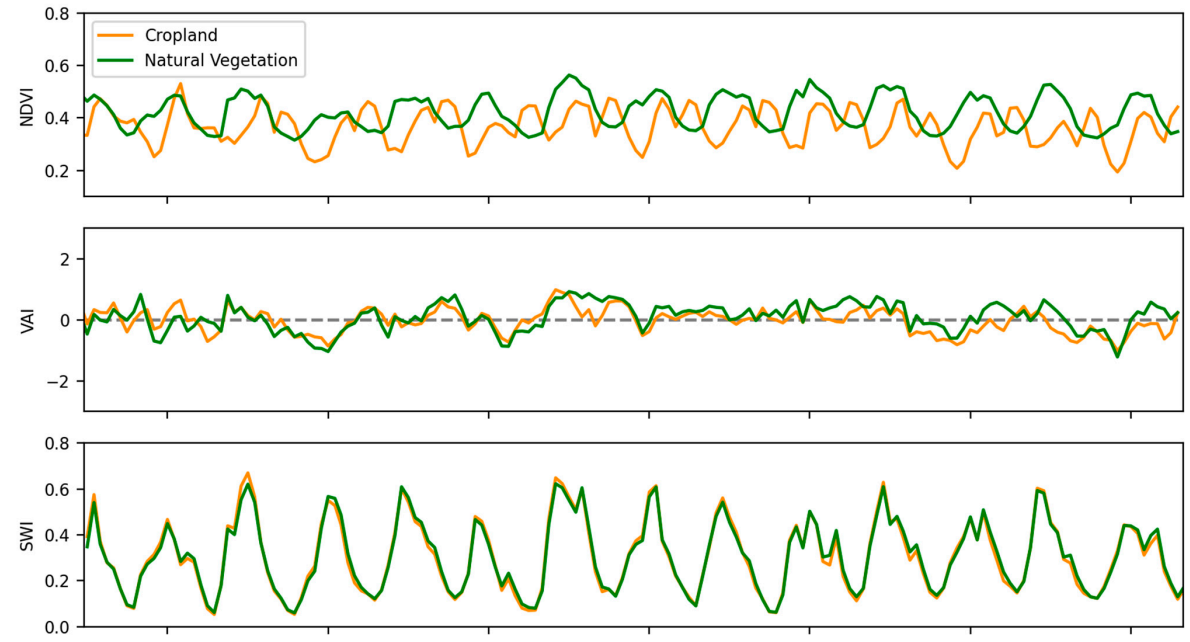

年A

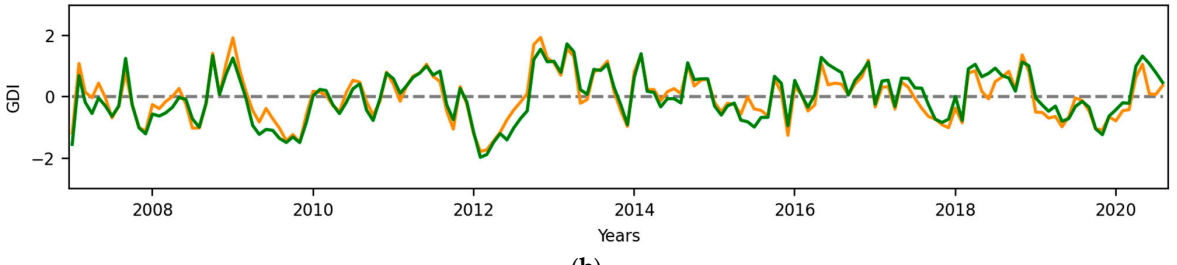

(b)

Figure 10. NDVI, SWI, VAI, MAI, and GDI time series at two test sites (a) Kairouan and (b) Andalusia. 
At the Kairouan site (Figure 10a), the trends of the two indices seemed to be strongly correlated for both land cover types in cropland and natural vegetation. In fact, at this site, the type of rainfed agriculture explained this correlation between the water stock in the soil and the dynamics of the vegetation cover. On the other hand, at the irrigated site in Andalusia (Figure 10b), strong differences were first observed between the two types of land cover linked to different vegetation cycles. The MAI and VAI also showed different trends. This result could be explained by the effect of irrigation on the dynamics of the vegetation cover, independent of the actual rainfall context. In this context, the application of the GDI index aims to consider the effects related to vegetation and soil water content through the combination of VAI and MAI.

\subsubsection{GDI Combined Index Application}

Figure 11 illustrates parameters $\alpha$ and $\beta$ defined in Section 2.2 .3 for $\alpha 0$ and $\beta 0$, respectively, equal to 0.1 at the two study sites in Kairouan and Andalusia. The values of $\alpha 0$ and $\beta 0$ were chosen empirically to define the minimum weights of the VAI and MAI indices. The larger these values, the more we move towards an identical weighting of the two indices as applied by other existing drought indices.

For the former, slight discrepancies between the different weights proposed for the two types of cover were observed. This result was related to the rainfall context of this study area and the different spatial resolutions of the two remote sensing products used. In Kairouan, the alpha cycles were similar between cropland and natural vegetation; however, some differences were observed. In particular, $50 \%$ of the boxes were much smaller for the natural vegetation between October and January, which illustrates more variability during this period when the start of the agricultural season with the first cereal seeding was very variable between farmers and more variability from one year to another due to rainfall.

Minimum weights were observed in July and August and corresponded to the weight with the lowest vegetation cover and the lowest soil water storage. These weights were close to 0.1 , the minimum, and illustrate the limitations of the calculation of a drought index in this context with too weak effects on the almost nonexistent vegetation cover and the very low water stock.

In Kairouan (Figure 11a), variations in $\alpha$ and $\beta$ were rarely above 0.2 for cropland and natural vegetation; however, $\alpha$ showed wide variation for Andalusia croplands, probably due to the high percentage of irrigated areas and intense crop rotations, while $\alpha$ variation for the natural vegetation areas remained under 0.2. Slight differences in the weights existed in autumn and spring. The Andalusia site (Figure 11b) illustrates additional uncorrelated relationships between canopy dynamics and water content stock, particularly due to irrigation in agricultural areas. A higher dispersion of $\beta$ was observed in the months of March and April, suggesting that the low-resolution remote sensing product of soil moisture could identify the impact of irrigation. In this framework, weights $\alpha$ and $\beta$ are only correlated in the case of natural canopies.

Figure 10 shows the values of VAI, MAI, and GDI at the two sites Kairouan and Andalusia, during the last 13 years. At the Kairouan site (Figure 10a), we see strong similarities between the drought indices estimated on the two classes, croplands and natural vegetation, in the context of mainly rainfed agriculture. At the Andalusia site (Figure 10b), the correlation between VAI and MAI is weaker. The effect of irrigation is probably very important. GDI more clearly combines the effects of drought on vegetation and soil water content. 

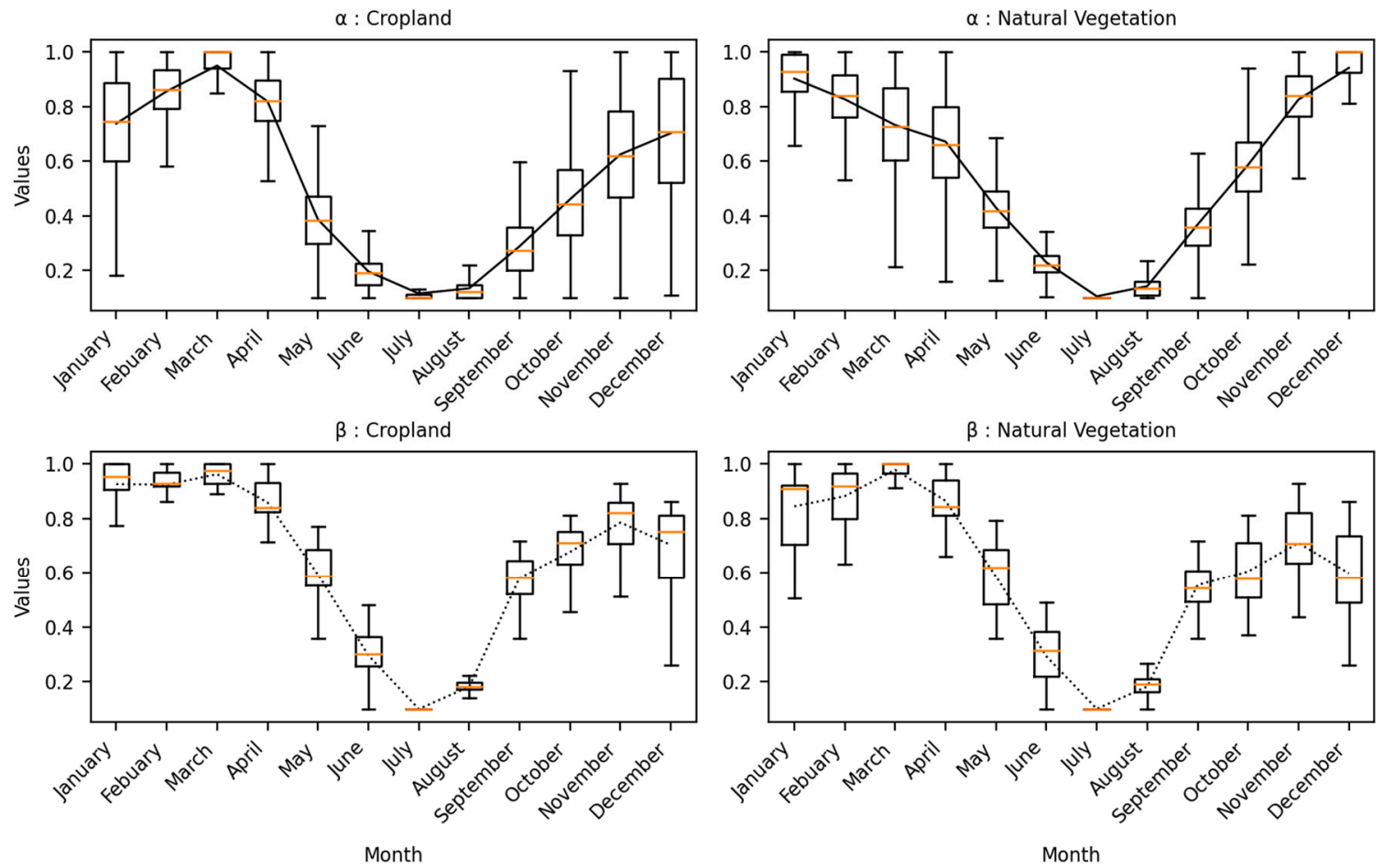

(a)
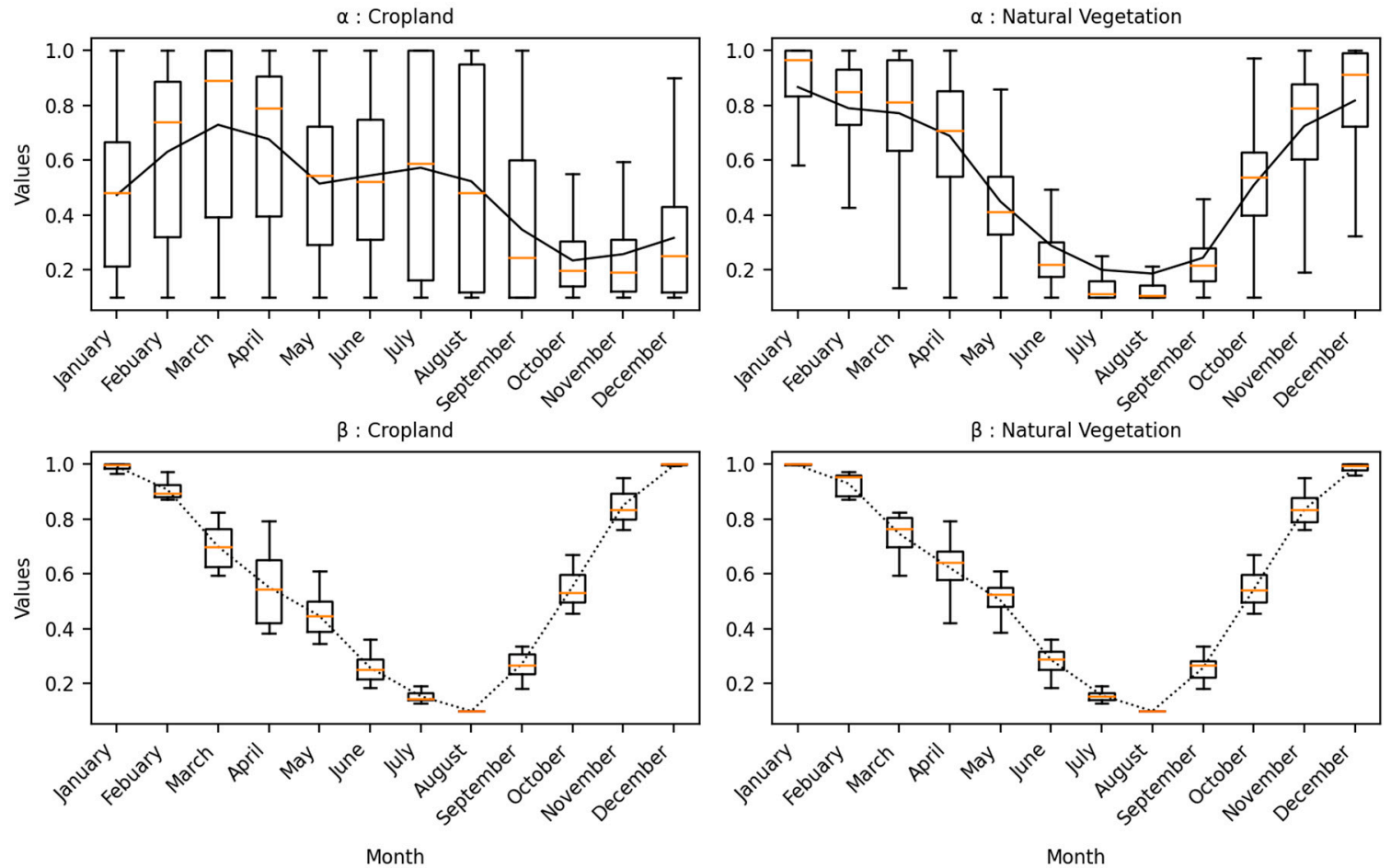

(b)

Figure 11. Illustration of $\alpha$ and $\beta$ weight parameters for each type of land use (cropland and natural vegetation) for (a) Kairouan and (b) Andalusia.

\subsubsection{Mapping of the GDI}

Figure 12 illustrates the mapping of the GDI with the proposed weights described in Equations (5) and (6) in March 2016 (dry year) and March 2018 (wet year). The patterns were approximately similar to those in the VAI maps of Figure 6. However, compared to 
the VAI map, the new map accentuates the effect of drought in 2016 on the entire study region. It also shows a wetter index in 2018. As noted, with GDI, we have a drought map that combines the effects of drought on vegetation and on the water content in the soil. For example, on the Andalusia site, we observe a context with a positive GDI index in 2018 when it was negative with the VAI index. This is explained by a positive MAI index level as illustrated in Figure 10.

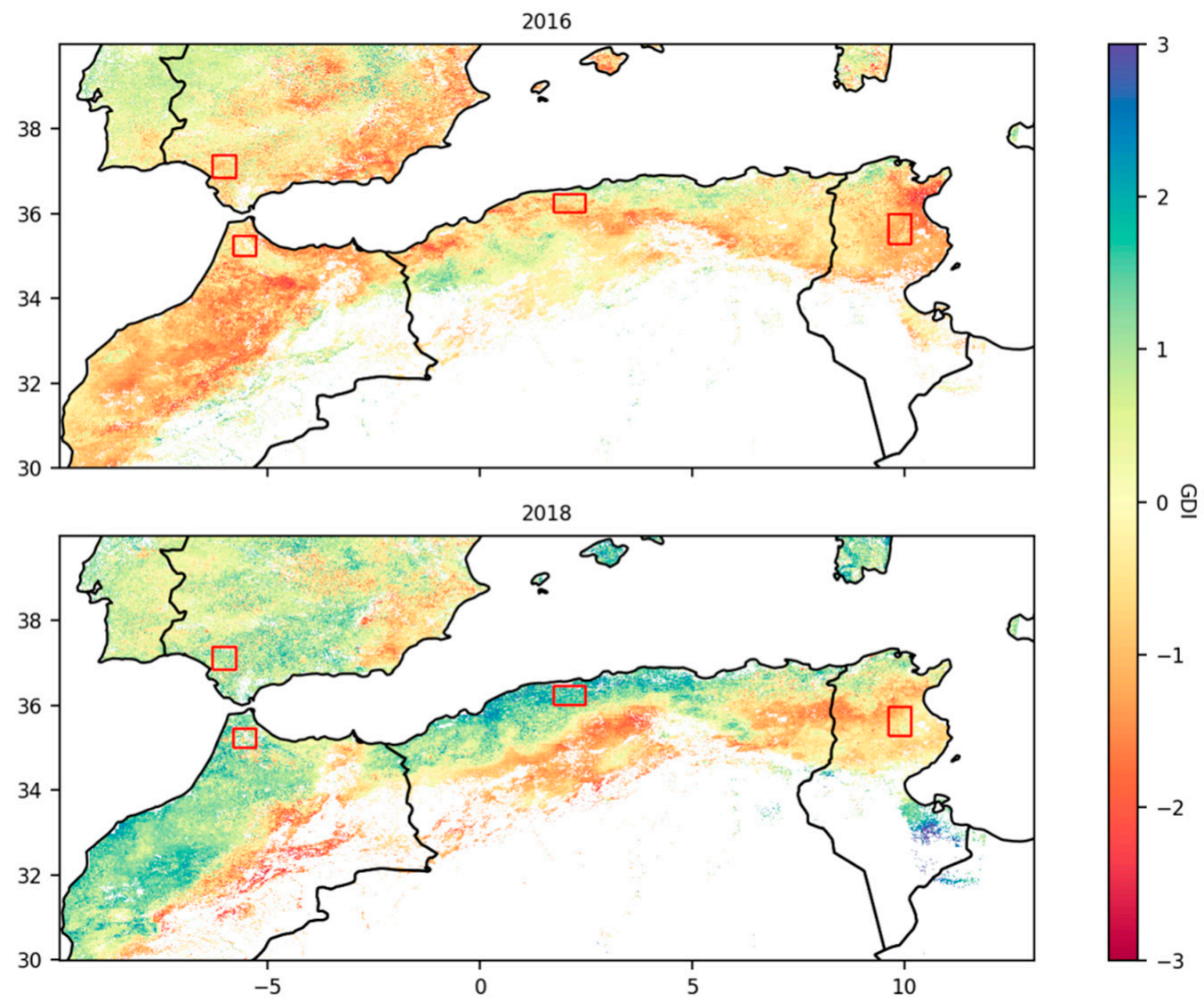

Figure 12. Illustration of land use and GDI mapping over the studied region for March 2016 and March 2018.

When we look closely at the sites of Kairouan (Figure 13) and Andalusia (Figure 14), for example, during the entire hydrological year 2015-2016, which was particularly dry, we observed approximately the same spatial trends between the two indices VAI and GDI. However, the intensity of the indices was not the same. We observe similar behaviors during the summer dry season. On the other hand, during the other seasons, the intensity of the drought was not the same. The difference is more marked on the highly irrigated Andalusia site, sometimes with an intensification of the drought index as observed in autumn and inversely at the end of spring. 

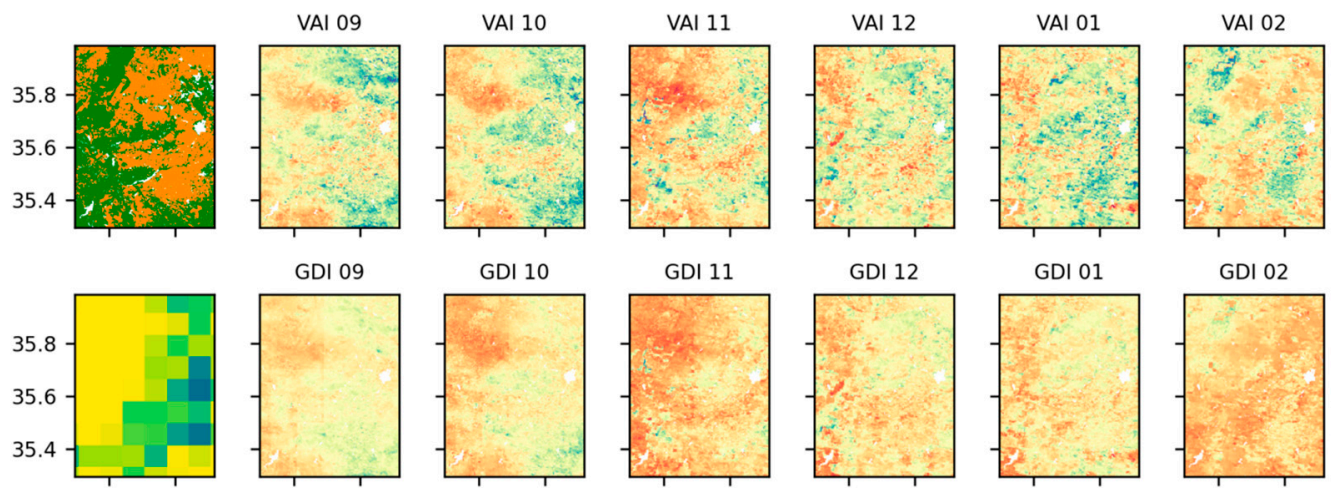

GDI 02
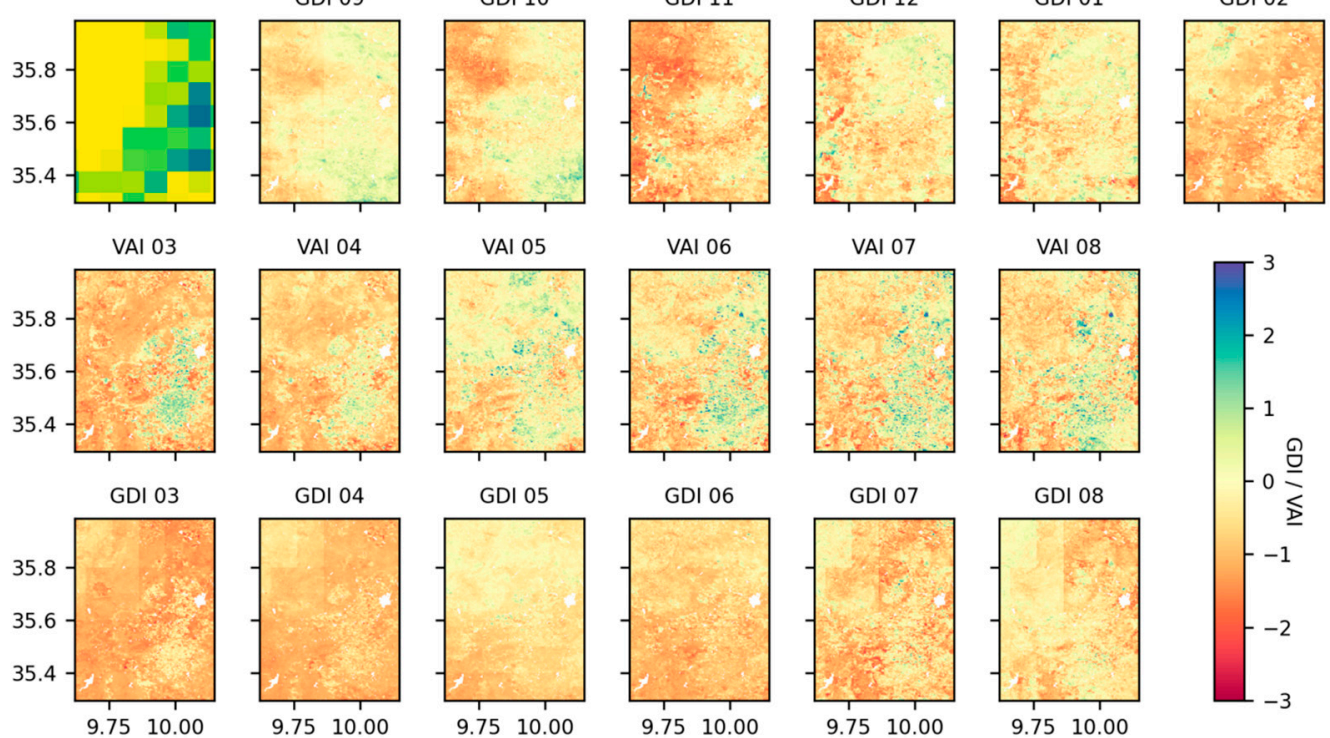

Figure 13. Illustration of maps of land use, irrigation, VAI, and GDI during the 2015-2016 season for each month, from September to August, over the Kairouan site.
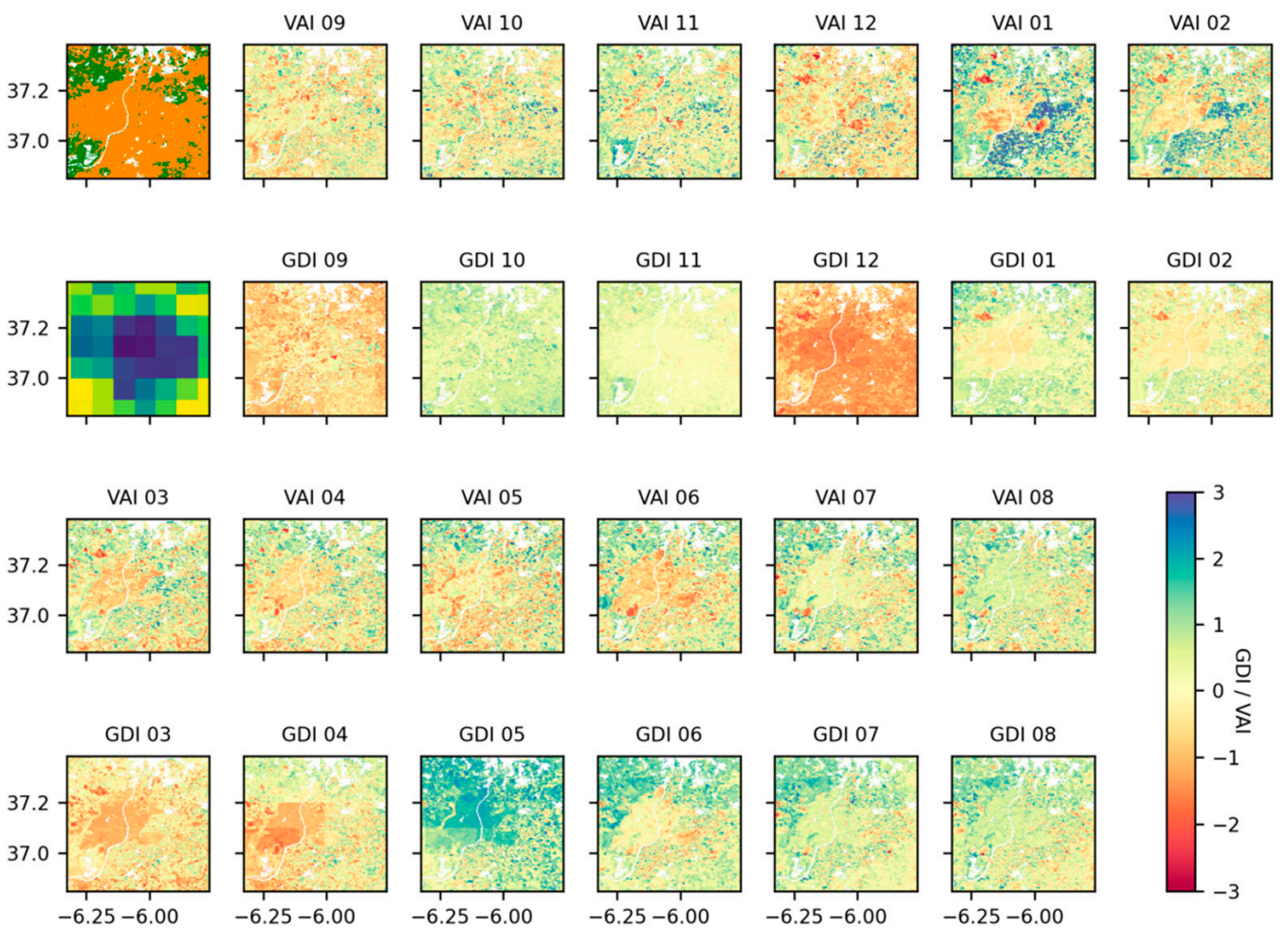

Figure 14. Illustration of maps of land use, irrigation, VAI, and GDI during the 2015-2016 season, for each month from September to August, over the Andalusia site. 


\section{Conclusions}

A drought analysis was conducted over regions in North Africa and southern Spain using satellite time series data, with NDVI products from optical MODIS data and soil water content products from ASCAT microwave measurements. Drought analysis was conducted first using the VAI index based on the NDVI. The effect of land cover type was discussed. There was a general increase in the drought indices over agricultural areas compared to that over other natural land covers (shrub and forests). The drought indices calculated in these agricultural areas showed less correlation with the indices calculated for the other natural land cover types compared to comparisons made between the natural cover types. This result can be explained by the anthropogenic effect, which can be relatively important in agricultural areas, particularly due to irrigation. The mapping of the VAI index was estimated separately for the two land-use classes, croplands and natural areas, which were composed of shrubs and forests.

To complete the information related to the vegetation cover, a new index, the GDI that combined NDVI information with water content information through the SWI was also proposed. This index is the combination of the VAI and MAI indices, weighted with variable weights depending on the seasonal context of precipitation and vegetation development or human action such as irrigation. The purpose of this variable weighting was to take into account more or less important effects according to the monthly average of the variable in each study month. Mapping of the GDI parameters was proposed over the studied region.

Author Contributions: M.Z. and S.N. conceived and designed the experiments; S.N., M.Z., and M.L.P. analyzed the data; all authors contributed to the materials/analysis tools; M.Z. and S.N. wrote the paper. All authors reviewed the paper writing. All authors have read and agreed to the published version of the manuscript.

Funding: This research was funded by TAPAS (TOSCA/CNES) and CHAAMS (ERANET3-602 CHAAMS) projects.

Institutional Review Board Statement: Not applicable.

Informed Consent Statement: Not applicable.

Data Availability Statement: TERRA-MODIS NDVI data are available online from NASA site. The ASCAT SWI and land use products are available online from the Coperni-cus Global Land service.

Conflicts of Interest: The authors declare no conflict of interest.

\section{References}

1. Wilhite, D.A.; Svoboda, M.D.; Hayes, M.J. Understanding the complex impacts of drought: A key to enhancing drought mitigation and preparedness. Water Resour. Manag. 2007, 21, 763-774. [CrossRef]

2. FAO. The State of the World's Land and Water Resources for Food and Agriculture (SOLAW)—Managing Systems at Risk; Food and Agriculture Organization of the United Nations, Rome and Earthscan: London, UK, 2011; ISBN 978-1-84971-327-6.

3. McKee, T.B.; Doesken, N.J.; Kleist, J. The relationship of drought frequency and duration to time scales. In Proceedings of the 8th Conference on Applied Climatology of American Meteorological Society, Anaheim, CA, USA, 7-22 January 1993.

4. Cook, E.R.; Seager, R.; Cane, M.A.; Stahle, D.W. North American drought: Reconstructions, causes, and consequences. Earth Sci. Rev. 2007, 81, 93-134. [CrossRef]

5. Cook, B.I.; Mankin, J.; Anchukaitis, K.J. Climate Change and Drought: From Past to Future. Curr. Clim. Chang. Rep. 2018, 4, 164-179. [CrossRef]

6. Heim, R.R. A review of twentieth-century drought indices used in the United States Bull. Am. Meteorol. Soc. 2002, 84, 1149-1165. [CrossRef]

7. Scheff, J. A unified wetting and drying theory. Nat. Clim. Chang. 2019, 9, 9-10. [CrossRef]

8. Tramblay, Y.; Koutroulis, A.; Samaniego, L.; Vicente-Serrano, S.M.; Volaire, F.; Boone, A.; Le Page, M.; Llasat, M.C.; Albergel, C.; Burak, S.; et al. Challenges for drought assessment in the Mediterranean region under future climate scenarios. Earth-Sci. Rev. 2020, 210, 103348. [CrossRef]

9. McKee, T.B.; Doesken, N.J.; Kleist, J. Drought monitoring with multiple time scales. In Proceedings of the 9th Conference on Applied Climatology of American Meteorological Society, Dallas, TX, USA, 15-20 January 1995. 
10. Vicente-Serrano, S.M.; Beguería, S.; López-Moreno, J.I. A Multi-scalar drought index sensitive to global warming: The standardized precipitation evapotranspiration index-SPEI. J. Clim. 2010, 23, 1696-1718. [CrossRef]

11. Palmer, W.C. Meteorologic Drought; Research Paper; U.S. Department of Commerce, Weather Bureau: Washington, DC, USA, 1965.

12. Alley, W.M. The Palmer drought severity index: Limitations and assumptions. J. Clim. Appl. Meteor. 1984, 23, 1100-1109. [CrossRef]

13. Kogan, F.N. Application of vegetation index and brightness temperature for drought detection. Adv. Space Res. 1995, 15, 91-100. [CrossRef]

14. Kogan, F.N. Global Drought Watch from Space. Bull. Am. Meteorol. Soc. 1997, 78, 621-636. [CrossRef]

15. Kogan, F.N. Contribution of Remote Sensing to Drought Early Warning. In Early Warning Systems for Drought Preparedness and Drought Management; Wilhite, D.A., Wood, D.A., Eds.; World Meteorological Organization: Geneva, Switzerland, $2000 ;$ pp. 75-87.

16. Habets, F.; Gascoin, S.; Korkmaz, S.; Thiery, D.; Zribi, M.; Amraoui, N.; Carli, M.; Ducharne, A.; Leblois, E.; LeDoux, E.; et al. Multi-model comparison of a major flood in the groundwater-fed basin of the Somme River (France). Hydrol. Earth Syst. Sci. 2010, 14, 99-117. [CrossRef]

17. Massari, C.; Brocca, L.; Moramarco, T.; Tramblay, Y.; Lescot, J.F.D. Potential of soil moisture observations in flood modelling estimating initial conditions and correcting rainfall. Adv. Water Resour. 2014, 74, 44-53, ISSN 0309-1708. [CrossRef]

18. Entekhabi, D.; Njoku, E.G.; O’Neill, P.E.; Kellogg, K.H.; Crow, W.T.; Edelstein, W.N.; Entin, J.K.; Goodman, S.D.; Jackson, T.J.; Johnson, J.; et al. The Soil Moisture Active Passive (SMAP) Mission. Proc. IEEE 2010, 98, 704-716. [CrossRef]

19. Saux-Picart, S.; Ottlé, C.; Decharme, B.; André, C.; Zribi, M.; Perrier, A.; Coudert, B.; Boulain, N.; Cappelaere, B.; Descroix, L.; et al. Water and energy budgets simulation over the AMMA-Niger super-site spatially constrained with remote sensing data. J. Hydrol. 2009, 375, 287-295. [CrossRef]

20. Kogan, F.N. Operational space technology for global vegetation assessment. Bull. Am. Meteorol. Soc. 2001, 82, 1949-1964. [CrossRef]

21. Ji, L.; Peters, A.J. Assessing vegetation response to drought in the northern Great Plains using vegetation and drought indices. Remote. Sens. Environ. 2003, 87, 85-98. [CrossRef]

22. Singh, R.P.; Roy, S.; Kogan, F. Vegetation and temperature condition indices from NOAA AVHRR data for drought monitoring over India. Int. J. Remote Sens. 2003, 24, 4393-4402. [CrossRef]

23. Amri, R.; Zribi, M.; Lili-Chabaane, Z.; Wagner, W.; Hauesner, S. Analysis of ASCAT-C band scatterometer estimations derived over a semi-arid region. IEEE Trans. Geosic. Remote Sens. 2012, 50, 2630-2638. [CrossRef]

24. Al Bitar, A.; Kerr, Y.; Merlin, O.; Cabot, F.; Wigneron, J.P. Global drought index from SMOS soil moisture. In Proceedings of the IEEE International Geoscience and Remote Sensing Symposium, IGARSS 2013, Melbourne, Australia, 21-26 July 2013.

25. Sánchez, N.; González-Zamora, A.; Piles, M.; Martínez-Fernández, J. A New Soil Moisture Agricultural Drought Index (SMADI) Integrating MODIS and SMOS Products: A Case of Study over the Iberian Peninsula. Remote Sens. 2016, 8, 287. [CrossRef]

26. Mu, Q.; Zhao, M.; Kimball, J.S.; McDowell, N.G.; Running, S.W. A Remotely Sensed Global Terrestrial Drought Severity Index. Bull. Am. Meteorol. Soc. 2013, 94, 83-98. [CrossRef]

27. Tucker, C.J. Red and photographic infrared linear combinations for monitoring vegetation. Remote Sens. Environ. 1979, 8, 127-150. [CrossRef]

28. Seiler, R.; Kogan, F.; Wei, G. Monitoring weather impact and crop yield from NOAA AVHRR data in Argentina. Adv. Space Res. 2000, 26, 1177-1185. [CrossRef]

29. Quiring, S.M.; Ganesh, S. Evaluating the utility of the Vegetation Condition Index (VCI) formonitoring meteorological drought in Texas. Agric. For. Meteorol. 2010, 150, 330-339. [CrossRef]

30. Gitelson, A.; Kogan, F.; Zakarin, E.; Spivak, L.; Lebed, L. Using AVHRR data for quantitive estimation of vegetation conditions: Calibration and validation. Adv. Space Res. 1998, 22, 673-676. [CrossRef]

31. Amri, R.; Zribi, M.; Lili-Chabaane, Z.; Duchemin, B.; Gruhier, C.; Chehbouni, A. Analysis of Vegetation Behavior in a North African Semi-Arid Region, Using SPOT-VEGETATION NDVI Data. Remote Sens. 2011, 3, 2568-2590. [CrossRef]

32. Zribi, M.; Dridi, G.; Amri, R.; Chabaane, Z.L. Analysis of the Effects of Drought on Vegetation Cover in a Mediterranean Region through the Use of SPOT-VGT and TERRA-MODIS Long Time Series. Remote Sens. 2016, 8, 992. [CrossRef]

33. Jarlan, L.; Abaoui, J.; Duchemin, B.; Ouldbba, A.; Tourre, Y.M.; Khabba, S.; Le Page, M.; Balaghi, R.; Mokssit, A.; Chehbouni, G. Linkages between common wheat yields and climate in Morocco (1982-2008). Int. J. Biometeorol. 2013, 58, 1489-1502. [CrossRef] [PubMed]

34. Jiménez-Donaire, M.D.P.; Tarquis, A.; Giraldez, J. Evaluation of a combined drought indicator and its potential for agricultural drought prediction in southern Spain. Nat. Hazards Earth Syst. Sci. 2020, 20, 21-33. [CrossRef]

35. Jiao, W.; Tian, C.; Chang, Q.; Novick, K.A.; Wang, L. A new multi-sensor integrated index for drought monitoring. Agric. For. Meteorol. 2019, 268, 74-85. [CrossRef]

36. Sanchez, N.; González-Zamora, Á.; Martínez-Fernández, J.; Piles, M.; Pablos, M. Integrated remote sensing approach to global agricultural drought monitoring. Agric. For. Meteorol. 2018, 259, 141-153. [CrossRef]

37. Le Page, M.; Zribi, M. Analysis and Predictability of Drought In Northwest Africa Using Optical and Microwave Satellite Remote Sensing Products. Sci. Rep. 2019, 9, 1466. [CrossRef]

38. Kogan, F.; Guo, W.; Yang, W. Near 40-year drought trend during 1981-2019 earth warming and food security. Geomat. Nat. Hazards Risk 2020, 11, 469-490. [CrossRef] 
39. Vermote, E.F.; El Saleous, N.Z.; O Justice, C. Atmospheric correction of MODIS data in the visible to middle infrared: First results. Remote Sens. Environ. 2002, 83, 97-111. [CrossRef]

40. Justice, C.; Townshend, J.; Vermote, E.; Masuoka, E.; Wolfe, R.; Saleous, N.; Roy, D.; Morisette, J. An overview of MODIS Land data processing and product status. Remote Sens. Environ. 2002, 83, 3-15. [CrossRef]

41. Wagner, W. Soil Moisture Retrieval from ERS Scatterometer Data; Technische Universität Wien: Vienna, Austria, 1998.

42. Wagner, W.; Lemoine, G.; Rott, H. A method for estimating soil moisture from ERS scatterometer and soil data. Remote Sens. Environ. 1999, 70, 191-207. [CrossRef]

43. Zribi, M.; Anguela, T.P.; Duchemin, B.; Lili, Z.; Wagner, W.; Hasenauer, S.; Chehbouni, A. Relationship between soil moisture and vegetation in the Kairouan plain region of Tunisia using low spatial resolution satellite data. Water Resour. Res. 2010, 46. [CrossRef]

44. Buchhorn, M.; Smets, B.; Bertels, L.; De Roo, B.; Lesiv, M.; Tsendbazar, N.-E.; Herold, M.; Fritz, S. Copernicus Global Land Service: Land Cover 100m: Collection 3: Epoch 2019: Globe. 2020. Available online: https:/ / zenodo.org/record/3939050\#.YOes1UwRVPY (accessed on 1 July 2021).

45. Available online: http://www.fao.org/aquastat/en/geospatial-information/global-maps-irrigated-areas (accessed on 1 July 2021).

46. Döll, P.; Siebert, S. A Digital Global Map of Irrigated Areas. ICID J 2000, 49, 55-66.

47. Siebert, S.; Döll, P.; Hoogeveen, J.; Faures, J.-M.; Frenken, K.; Feick, S. Development and validation of the global map of irrigation areas. Hydrol. Earth Syst. Sci. 2005, 9, 535-547. [CrossRef]

48. Zribi, M.; Nativel, S.; Le Page, M. Analysis of agronomic drought over North Africa using remote sensing satellite data. In EGU General Assembly Conference Abstract; EGU: Munich, Germany, 2021.

49. Available online: https://www.mapa.gob.es/es/estadistica/temas/estadisticas-agrarias/agricultura/esyrce/ (accessed on 1 July 2021). 